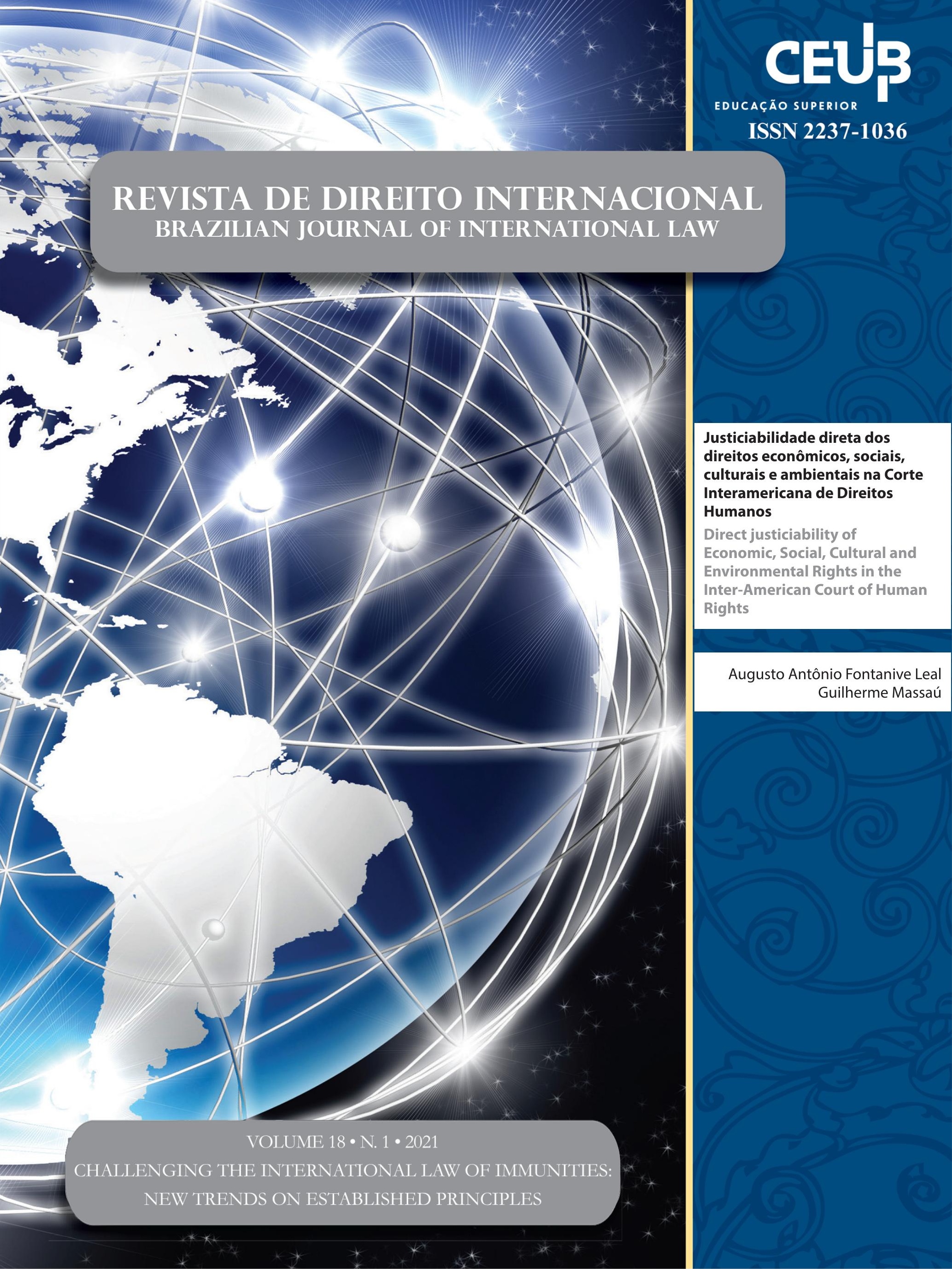


EDITORIAL

Challenging the International Law of Immunities: New Trends on Established Principles? An introduction to the special issue ............................................ 14

Lucas Carlos Lima, Loris Marotti e Paolo Palchetti

CrôniCAS........................................................................................ 17

RESPONSABILIDADE E IMUNIDADE DAS ORgANIZAÇÕES INTERNACIONAIS: PRÁTICA E DESAFIOS ...19 Vinícius Fox Drummond Cançado Trindade

The JURISDiCTIONAL IMMUNITY OF INTERNATIONAL ORgaNiZATIONS BEFORE THE BRAZILIAN SuPREMe Federal Court.

Bárbara Tuyama Sollero

The Law of State Immunity before the Brazilian Supreme Court: what is at stake WITH THE "ChANGRI-LA" CASE?

Aziz Tuffi Saliba e Lucas Carlos Lima

\section{Dossiê: Challenging the International Law of Immunities: New Trends} on Established Principles?

State Immunity and the Rights of Employees: Lights and Shadows of the Strasbourg COURT's JURISPRUdENCE .61

Pierfrancesco Rossi

A human Rights-BASEd CHALlENGE: THE KEY TO UNLOCK THE UN'S IMMUNiTY PROBLEM?...79 Héloïse Guichardaz

IMMUNITIES OF STATE OFFICIALS AND THE "FUNDAMENTALLY DIFFERENT NATURE" OF INTERNATIONAL COURTS: THE APPEALS CHAMBER DECISION IN THE JORDAN REFERRAL RE AL BASHIR ...97 Rita Guerreiro Teixeira e Hannes Verheyden 
IMUNIDADE DE JURISDIÇÃo dOS EsTADOS: O CAMINHO PARA A RELATIVIZAÇÃo

Vinícius Assis da Silveira, Luiz Felipe Costa Santana e Valesca Raizer Borges Moschen

The IMmUNity OF INTERNATIONAL ORganizations IN LABOUR DispUTES. DeVElopments BEFORE INTERNATIONAL TRIBUNALS, NATIONAL COURTS AND THE COLOMBIAN JURISDICTION ..... 137 Walter Arévalo-Ramirez e Ricardo Abello-Galvis

Imunidade de Jurisdição dos Estados E Poder Executivo brasileiro: os Pareceres dos CONSULTORES JURÍDICOS DO ITAMARATY

George Rodrigo Bandeira Galindo

Artigos SOBRe outros temas

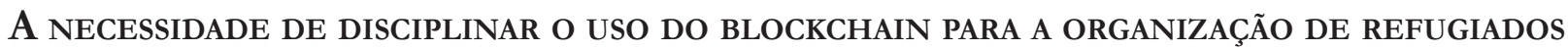
PELO DIREITO INTERNACIONAL. 195

Agatha Gonçalves Santana, Carla Noura Teixeira e Otavio Noura Teixeira

O TRABALHO INFANTIL DE MIGRANTES E REFUgIADOS VENEZUELANOS NO BRASIL

André Viana Custódio e ohana Cabral

THE NEW BRAZILIAN ANTI-TRAFFICKING LAW: CHALLENGES AND OPPORTUNITIES TO COVER THE NORMATIVE LACK . 243 Waldimeiry Correa da Silva

¿SON PARTE DEL BLOQUE DE CONSTITUCIONALIDAD LOS TRATADOS INTERNACIONALES DE DERECHOS HuMANOS DE LA OEA EN CHILE?: AVANCES EN BASE A LA DOCTRINA, NORMATIVA Y JURISPRUDÊNCIA. 270

Juan Pablo Díaz Fuenzalida

O Tratado de Saint-Germain-En-Laye e os Efeitos do instituto da “opÇão” Sobre a CONDIÇÃO JURÍDICA DOS DESCENDENTES DE CIDADÃOS AUSTRÍACOS TRENTINO-TIROLÊSES ......290 Arno Dal Ri Jr. e Andrey José Taffner Fraga

Control Judicial de la Corte Interamericana de Derechos Humanos y Programas Masivos de Reparaciones: Hacia un Enfoque más Matizado .309 Juan Carlos Ochoa-Sánchez 
JuSTICIABILIDADE DIRETA DOS DIREITOS ECONÔMICOS, SOCIAIS, CULTURAIS E AMBIENTAIS NA

Corte Interamericana DE Direitos Humanos..........................................................334

Augusto Antônio Fontanive Leal e Guilherme Massaú

How the indigenous case of Xukuru before the Inter-American Court of Human RiGHTS CAN INSPIRE DECOLONIAL COMPARATIVE STUDIES ON PROPERTY RIGHTS..........................353

Flavianne Fernanda Bitencourt Nóbrega e Camilla Montanha 


\title{
Justiciabilidade direta dos direitos econômicos, sociais, culturais e ambientais na Corte Interamericana de Direitos Humanos*
}

\author{
Direct justiciability of Economic, Social, \\ Cultural and Environmental Rights in the \\ Inter-American Court of Human Rights
}

\author{
Augusto Antônio Fontanive Leal** \\ Guilherme Massaú***
}

\section{Resumo}

O texto tem como objetivo mostrar a mudança de interpretação da Corte Interamericana de Direitos Humanos no que tange à justiciabilidade direta baseada no artigo 26 da Convenção Americana de Direitos Humanos, justificando-se a adoção dessa temática em razão da importância dessa novel interpretação da Corte para um elevado número de Estados que se submetem a seus julgamentos. Conclui-se que, além de uma mudança de interpretação, houve a mudança de interpretação em uma nova perspectiva protetiva aos Direitos Econômicos, Sociais, Culturais e Ambientais (DESCA), que antanho ingressavam de forma indireta, ou reflexa, à Corte IDH. Isso, por conseguinte, leva a algumas consequências como uma maior proteção aos DESCA no sentido internacional e uma maior pressão aos Estados em efetivá-los de forma progressiva. O método de abordagem utilizado é o hipotético-dedutivo, pelo qual se avalia a hipótese de terem ocorrido mudanças na Corte Interamericana, realizando-se a pesquisa com base nos instrumentos internacionais que a vinculam legalmente, bem como nas demais interpretações doutrinárias e jurisprudenciais aplicáveis.

Palavras-chave: Corte Interamericana de Direitos Humanos. Direitos econômicos sociais, culturais e ambientais. Justiciabilidade.

* Recebido em 18/12/2020

Aprovado em 05/04/2021

** Doutor em Direito pela Pontifícia Universidade Católica do Rio Grande do Sul (PUCRS).

E-mail: augustoafleal@gmail.com

*** Professor da Faculdade e do Mestrado em Direito da UFPel; Pós-doutor na PUCRS; Doutor em Direito pela Unisinos; Mestre em Ciências Jurídico-Filosóficas pela Universidade de Coimbra.

E-mail: uassam@gmail.com

\section{Abstract}

Our purpose is to show the change of interpretation of the Inter-American Court of Human Rights regarding the direct justiciability based on article 26 of the American Convention on Human Rights, which is justified due to the importance of this new interpretation of the Court for a large number of states that submit to its judgments. We conclude that besides the change of interpretation, there is a new protective perspective to the Economic, Social, Cultural and Environmental Rights, which previously was just object of indirect analysis by the Inter-American Court of Human Rights. This leads to some consequences such as a greater protection to the Economic, Social, 
Cultural and Environmental Rights in the international sense and a greater pressure to States to implement them in a progressive way. The method of approach is the hypothetical-deductive, by which the hypothesis that these change have occurred in the Inter-American Court is evaluated, based on the international instruments that legally bind it, as well as the other applicable doctrinal and jurisprudential interpretations.

Keywords: Inter-American Court of Human Rights. Economic, social, cultural and environmental rights. Justiciability.

\section{Introdução}

Além da importância do sistema global de proteção dos direitos humanos, cumprem relevante função os sistemas regionais de proteção, dentre eles o Sistema Interamericano, o Sistema Europeu e o Sistema Africano. O Sistema Interamericano, sobre o qual se baseia este estudo, é formado por quatro instrumentos básicos: a Carta da Organização dos Estados Americanos de 1948 (Carta da OEA), a Declaração Americana dos Direitos e Deveres do Homem de 1948, a Convenção Americana sobre Direitos Humanos (CADH) de 1969, conhecida também como Pacto de San José da Costa Rica e o Protocolo Adicional à Convenção Americana em Matéria de Direitos Econômicos, Sociais e Culturais de 1988, denominado, simplesmente, de Protocolo de San Salvador (PSS).

O regime de proteção de direitos humanos que vigora no cenário interamericano é dotado de estrutura ampla, inclusive pioneira em alguns aspectos, como no caso de a CADH ter sido o primeiro tratado internacional de direitos humanos a fazer referência direta à proteção dos Direitos Econômicos, Sociais e Culturais (DESC) ${ }^{1}$. Porém, apesar do vasto repertório de normas voltadas à proteção dos direitos humanos, o Sistema Interamericano não está imune a controvérsias tampouco a eventuais problemas em relação à implementação e exigibilidade dos direitos humanos por ele previstos.

Uma importante questão toma assento no debate jurídico, trata-se da justiciabilidade direta dos DESCA,

1 SEATZU, Francesco; TORRES, Amaya Ubeda de. The social charter of the OAS: a step forward in the enforcement of socioeconomic rights in the Americas? Netherlands Quarterly of Human Rights, v. 32, n. 2, p. 130-158, 2014. p. 147. diante da norma vaga e, ao mesmo tempo, abstrata contida no art. 26 da CADH. Essa temática passou a ser cada vez mais estudada e discutida. Décadas após o advento da $\mathrm{CADH}$, exigiram-se manifestações específicas da Corte IDH, que nos últimos anos, notadamente a partir de 2017, reconheceu a justiciabilidade direta dos DESCA com fundamento no art. 26 da CADH.

Em vista disso, questiona-se, neste estudo, a viabilidade jurídica da justiciabilidade direta dos DESCA analisada com base nas decisões selecionadas que foram proferidas pela Corte IDH. Para a organização textual desta proposta de estudo, o artigo será dividido em quatro capítulos. O capítulo 2 contém uma exposição dos arrimos normativos do entendimento sobre a justiciabilidade direta dos DESCA, expondo os argumentos básicos contrários e favoráveis a essa interpretação. No capítulo 3, constam os casos decididos pela Corte IDH que concretizaram o reconhecimento, por parte do tribunal, da justiciabilidade direta dos DESCA com base no art. 26 da CADH. E, no capítulo 4, serão estabelecidas as vinculações normativas que corroboram o atual entendimento interpretativo da Corte IDH. Por fim, à guisa de tecer algumas conclusões sobre o tema, no capítulo 5 são expostas possíveis tendências para o cenário regional de proteção dos direitos humanos, com base nesse novo rumo interpretativo e decisório tomado pela Corte IDH.

Contudo, cabe esclarecer que as decisões proferidas pela Corte IDH e os estudos doutrinários nem sempre fizeram menções diretas aos direitos econômicos, sociais, culturais e ambientais (DESCA), ocasiões em que se manteve, apenas, a abreviação "DESC", exatamente quando apropriada ao contexto em que fora extraída sua menção. Porém, ora se pretende enfatizar o termo "DESCA" sempre que possível, considerando-se o reconhecimento, pela própria Corte IDH, da inclusão do direito ao ambiente no rol de direitos protegidos pelo art. 26 da CADH em razão da obrigação dos Estados de alcançar um desenvolvimento integral conforme consta na Carta da OEA.

\section{A discussão sobre a justiciabilidade direta dos DESCA}

No Sistema Interamericano de Direitos Humanos, a controvérsia sobre a justiciabilidade direta dos DESCA 
representa um antigo debate doutrinário e jurisprudencial. Enquanto muito têm se argumentado em favor e contra justicibialidade, com base, principalmente, na interpretação do art. 26 da CADH e nas competências da Corte IDH, a Corte havia consolidado, anteriormente ao rumo decisório da última década, um sistema de proteção indireta ou por conexidade aos DESCA, realizado por meio do conteúdo e alcance dos direitos civis e políticos (DCP).

Antes da mais recente vertente de decisões da Corte IDH sobre a justiciabilidade direta dos DESCA, compunha um exemplo claro de interpretações sobre a possibilidade de atuação indireta ou reflexa da Corte IDH aquelas relacionadas à proteção ambiental, fundamentando-se essa alegação indireta ou reflexa decorrente de algum DCP em razão de não constar o direito humano ao ambiente, consagrado no art. 11 do PSS, incluído no rol de direitos passíveis de peticionamento individual, previstos no art. 19.6, também do PSS $^{2}$.

O debate jurídico e acadêmico sobre a justiciabilidade dos DESCA surge, em grande parte, porque a $\mathrm{CADH}$, observada como o instrumento de maior importância no Sistema Interamericano ${ }^{3}$, não previu, de forma específica, direitos sociais, culturais ou econômicos e apenas determinou, ao citá-los de maneira genérica, que os Estados os cumprissem de modo progressivo $^{4}$. Ainda que o art. 26 da $\mathrm{CADH}$ remetesse à Carta da OEA e às normas sobre os DESCA nela previstas, o seu texto normativo do artigo $26 \mathrm{CADH}$ gerou, e ainda gera, diversas dúvidas relativas à interpretação sobre a possibilidade da justiciabilidade direta dos DESCA. Em outras palavras, como referira Cançado Trindade, os DESCA foram destinados a serem absorvidos por normas econômicas, sociais e culturais da Carta da OEA, de modo que a $\mathrm{CADH}$ não conteve mais que um artigo a seu respeito, dispondo tão somente sobre o seu desenvolvimento progressivo à luz das normas da Carta da $\mathrm{OEA}^{5}$.

\footnotetext{
RESENDE, Augusto César Leite de. A tutela jurisdicional do direito bumano ao meio ambiente sadio perante a corte interamericana de direitos bumanos. Belo Horizonte: Fórum, 2015. p. 145; MAZZUOLI, Valério de Oliveira; TEIXEIRA, Gustavo de Faria Moreira. O direito internacional do meio ambiente e o greening da Convenção Americana sobre Direitos Humanos. Revista Direito GV, São Paulo, v. 9, n. 1, p. 199-242, jan./jun. 2013. p. 211.

3 PIOVESAN, Flávia. Direitos humanos e o direito constitucional internacional. 18 ed. São Paulo: Saraiva Educação, 2018. p. 355.

${ }^{4}$ PIOVESAN, Flávia. Direitos humanos e o direito constitucional internacional. 18 ed. São Paulo: Saraiva Educação, 2018. p. 357.

5 CANÇADO TRINDADE, Antônio Augusto. La Proteccion In-
}

Sendo assim, demonstram-se, neste capítulo, os expoentes e as bases das duas correntes sobre a justiciabilidade direta dos DESCA. A primeira favorável e, portanto, concorda com essa forma de proteção e, a segunda oferece uma reação negativa à possibilidade jurídica de inclusão dos DESCA no sistema de peticiomento individual previsto na $\mathrm{CADH}$.

\subsection{Abordagem favorável}

Uma interpretação da proteção dos DESCA com base na CADH e que culmina no reconhecimento da existência de sua justiciabilidade direta passa por cinco pontos específicos: (a) o preâmbulo da CADH; (b) art. 26 da CADH; (c) o art. 29 da CADH; (d) a Carta da OEA, reformada pelo Protocolo de Buenos Aires, e (e) art. 4 do PSS.

O preâmbulo da CADH, em dois momentos, traz a importância dos DESCA para a afirmação do conteúdo do tratado. Serviria o preâmbulo, por isso, como uma diretriz axiológica a indicar o contexto e o sentido das normas posteriormente previstas ao longo do tratado. Nesse sentido, consta no preâmbulo que

sólo puede realizarse el ideal del ser humano libre, exento del temor y de la miseria, si se crean condiciones que permitan a cada persona gozar de sus derechos económicos, sociales y culturales, tanto como de sus derechos civiles y políticos.

E, com menção ao reconhecimento mais expansivo de direitos econômicos e sociais na Carta da OEA, o que será particularmente importante para a compreensão do art. 26 da CADH, referiu-se no preâmbulo que o Protocolo de Buenos Aires de 1967 incorporou à Carta da OEA previsões normativas mais amplas sobre "derechos económicos, sociales y educacionales" e estabeleceu que "una convención interamericana sobre derechos humanos determinara la estructura, competencia y procedimiento de los órganos encargados de esa matéria".

$\mathrm{O}$ art. 26 da CADH constitui, além do preâmbulo, a única referência que a CADH faz aos DESCA, ao prever o comprometimento, por parte dos Estados membros, de adotar providências, a nível interno e no âmbito da cooperação internacional, para alcançar "progresiva-

ternacional de Los Derechos, Econômicos, Sociales y Culturales. In: CERDAS CRUZ, Rodolfo; NIETO LOAIZA, Rafael. Estudios básicos de derechos humanos. San José: IIDH, 1994, p. 48. 
mente la plena efectividad de los derechos que se derivan de las normas económicas, sociales y sobre educación, ciencia y cultura, contenidas en la Carta de la Organización de los Estados Americanos", mas isso na "medida de los recursos disponibles, por vía legislativa u otros medios apropriados".

$\mathrm{O}$ art. 29 da $\mathrm{CADH}$ tem por finalidade estabelecer normas de interpretação aplicáveis à $\mathrm{CADH}$ e proíbe, expressamente, interpretações do tratado que venham a

\begin{abstract}
a) permitir a alguno de los Estados Partes, grupo o persona, suprimir el goce y ejercicio de los derechos y libertades reconocidos en la Convención o limitarlos en mayor medida que la prevista en ella; b) limitar el goce y ejercicio de cualquier derecho o libertad que pueda estar reconocido de acuerdo con las leyes de cualquiera de los Estados Partes o de acuerdo con otra convención en que sea parte uno de dichos Estados; c) excluir otros derechos y garantías que son inherentes al ser humano o que se derivan de la forma democrática representativa de gobierno; e, d) excluir o limitar el efecto que puedan producir la Declaración Americana de Derechos y Deberes del Hombre y otros actos internacionales de la misma naturaliza.
\end{abstract}

As limitações à interpretação da $\mathrm{CADH}$ vinculam a sua aplicação de modo a impossibilitar qualquer entendimento a partir da convenção que venha a tolher os direitos nela reconhecidos, os direitos previstos no ordenamento jurídico doméstico de Estados membros ou demais direitos protegidos por outras convenções que tenham sido pelos Estados membros firmadas. Disso já se pode perceber que, tendo a $\mathrm{CADH}$, no artigo 26, previsto expressamente um direito a plena efetividade dos DESCA, no máximo seria possível controverter a respeito da sua forma de efetivação, pois o mesmo artigo menciona a realização desses direitos por uma via progressiva e em constância com as condições orçamentárias dos Estados. Ademais, em nenhum momento a norma contida no art. 26 da CADH deixa de reconhecer esses direitos, tampouco decreta a impossibilidade de sua justiciabilidade direta.

Além disso, o art. 26 da CADH não descreve, especificamente, quais dos DESCA está a proteger em suas linhas normativas, mas os indica claramente como aqueles direitos contidos na Carta da OEA após a reforma realizada pelo Protocolo de Buenos Aires. Isso quer dizer que aquelas normas econômicas, sociais e sobre educação, ciência e cultura que constam na Carta da OEA integram o conteúdo da CADH pela abertura e recepção decorrente do art. 26 desse instrumento normativo internacional e são, por força da abertura e classificação realizadas pelo referido art. 26, consideradas direitos integrantes da CADH.

$\mathrm{Na}$ Carta da OEA, constam, especificamente, no Capítulo VII, intitulado "desarrollo integral", diversas normas que se enquadram na moldura delimitada pelo artigo 26 da CADH, notadamente nos artigos 34, 45, 46 e 52. E, consoante o art. 106 da Carta, "una convención interamericana sobre derechos humanos determinará la estructura, competencia y procedimiento de dicha Comisión, así como los de los otros órganos encargados de esa matéria", ocasião em que se há de rememorar essa mesma menção no preâmbulo da CADH.

Essa análise interpretativa propicia, claramente, o entendimento de que os DESCA podem ser exigidos judicialmente de maneira direta, haja vista que, se o artigo 26 da CADH reconhece os DESCA previstos na Carta da OEA como albergados e protegidos pelo tratado, e, considerando-se que a $\mathrm{CADH}$, em seus artigos 1.1 e 2, vincula os Estados membros a respeitar os direitos e liberdades reconhecidas na convenção e a promover medidas cabíveis, inclusive legislativas, com a finalidade de os tornar efetivos, pouco espaço restaria para negar a sua justiciabilidade direta. Seria, por consequência, somente possível debater sobre os limites da tutela jurisdicional em razão de comandos de execução progressiva dos DESCA e dos limites orçamentárias, como delimitado pelo art. 26, in fine, da CADH.

Segundo a linha interpretativa em prol da justiciabilidade direta dos DESCA com fundamento no artigo 26 da CADH, persegue-se, inicialmente, uma desmistificação da ideia de que haveria um desinteresse por parte de alguns Estados em assegurar o catálogo dos DESCA da mesma forma como realizado em relação aos DCP. A esse respeito, é categórica a conclusão de Melish, que, ao realizar um amplo estudo dos trabalhos preparatórios (travaux préparatoires) da CADH, afirmou haver uma clara intenção de que os DESCA protegidos pelo artigo 26 não deveriam ser considerados como direitos de segunda classe, pois estão submetidos às mesmas condições gerais de obrigação a que foram submetidos os DCP e que constaram no Capítulo I da convenção. Assim, pela análise dos trabalhos preparatórios realizados, não haveria outra leitura do art. $26 \mathrm{da} \mathrm{CADH}$ que não fosse a de uma previsão de direitos específicos e 
protegidos, os quais seriam judicializáveis nos mesmos moldes dos $\mathrm{DCP}^{6}$.

Haveria, além disso, uma proibição de que o art. 19.6 do PSS fosse utilizado como um pretexto para limitar ou restringir a judicialização dos direitos consagrados no art. 26 da $\mathrm{CADH}$, advinda, diretamente, do art. $4^{\circ}$ do referido PSS 7 . Observe-se, além disso, que, segundo Melish, a impossibilidade decorrente do art. 19.6 de invocar direitos mediante peticionamento individual se dá somente pela judicialização com base no PSS, o que não implicaria a exclusão da possibilidade de judicialização desses direitos justamente por estarem protegidos pela $\mathrm{CADH}$ e pela Declaração Americana, uma vez que o PSS não altera a jurisdição dos órgãos interamericanos ${ }^{8}$.

No mesmo sentido, Calderón Gamboa se manifesta, contrariamente, à possibilidade de que o PSS, especificamente pelo que dispõe no seu art. 19.6, venha a limitar a competência decorrente do art. 26 da CADH, mesmo porque o próprio PSS, no art. 4, retira toda e qualquer possibilidade de ser utilizado como instrumento hábil a restringir direitos reconhecidos e vigentes em razão de legislações internas ou outras convenções internacionais?.

\footnotetext{
${ }^{6}$ MELISH, Tara J. Rethinking the "Less as More" thesis: supranational litigation of economic, social and cultural rights in the Americas. International Law and Politics, v. 39, p. 171-343, 2006. p. 229-230. É relevante notar que neste texto, a autora pretendeu se contrapor aos argumentos legais e factuais que levaram Cavallaro e Schaffer a sustentar a tese de uma restrita litigância dos DESCA, segundo a qual, então denominada less as more (menos como mais), uma menor litigância direta dos DESCA levaria a uma implementação maior destes direitos. CAVALLARO, James L.; SCHAFFER, Emily J. Less as More: rethinking supranational litigation of economic and social rights in the Americas. Hastings Law Journal, v. 56, p. 217-282, 2004. p. 219, 281.

MELISH, Tara J. Rethinking the "Less as More" thesis: supranational litigation of economic, social and cultural rights in the Americas. International Law and Politics, v. 39, p. 171-343, 2006. p. 232.

8 MELISH, Tara J. Rethinking the "Less as More" thesis: supranational litigation of economic, social and cultural rights in the Americas. International Law and Politics, v. 39, p. 171-343, 2006. p. 233-234. Neste sentido, Abramovich e Rossi referem que o direito à greve, implicitamente previsto no artigo $45 \mathrm{da}$ Carta da OEA, estaria compreendido no artigo 26 da CADH e pode ser matéria de petição individual ante a Corte IDH, sem prejuízo de sua exclusão da enumeração de direitos justiciáveis prevista no artigo 19.6 do Protocolo. Cf. ABRAMOVICH, Víctor; ROSSI, Julieta. La tutela de los derechos económicos, sociales y culturales en el artículo 26 de la Convención Americana sobre Derechos Humanos. Revista Estudios Socio-Jurídicos, v. 9, n. esp., p. 34-53, abr. 2007. p. 50.

9 CALDERÓN GAMBOA, Jorge. La puerta de la justiciabilidad de los derechos económicos, sociales, culturales y ambientales en el Sistema Interamericano: relevancia de la sentencia Lagos del Campo. In: FERRER MAC-GREGOR, Eduardo; MORALES ANTONI-
}

Com isso, o art. 26 da CADH consolida a obrigação afirmada pelos Estados signatários de tornar efetivos os DESC derivados da Carta da OEA ${ }^{10}$. A menção ao caráter progressivo não geraria, por si só, uma exclusão absoluta das obrigações estatais operativas e imediatamente exigíveis ${ }^{11}$.

AZZI, Mariela; FLORES PANTOJA, Rogelio. Inclusión, Ius Commune y justiciabilidad de los DESCA en la jurisprudencia interamericana: el caso Lagos del Campo y los nuevos desafios. Querétaro: Instituto de Estudios Constitucionales del Estado de Querétaro, 2018. p. 345-347. Daí porque o autor refere que segundo o artigo 30.2 da Convenção de Viena sobre o Direito dos Tratados de 1969, um tratado subordinado a outro que o especifique não deve ser considerado incompatível com este tratado, prevalecendo as disposições deste último. A utilização dos critérios hermenêuticos da Convenção de Viena apareceu na fundamentação da justiciabilidade direta do artigo 26 da CADH no caso Cuscul Pivaraly otros vs. Guatemala, que será mais adiante visto.

10 ABRAMOVICH, Víctor; ROSSI, Julieta. La tutela de los derechos económicos, sociales y culturales en el artículo 26 de la Convención Americana sobre Derechos Humanos. Revista Estudios Socio-Jurídicos, v. 9, n. esp., p. 34-53, abr. 2007. p. 39. Vejam-se ainda, sobre a defesa de uma justiciabilidade direta dos DESCA: ESTAPÀ, Jaume Saura. La exigibilidade jurídica de los derechos humanos: especial eferencia a los derechos econômicos, sociales y culturales (DESC). Papeles el Tempo de los Derechos, n. 2, p. 1-14, 2011. p. 7; ANTKOWIAK, Thomas. Social, economic, and cultural rights: the Inter-American Court at a Crossroads. In: HAECK, Yves; RUIZ-CHIRIBOGA, Oswaldo; BURBANO-HERRERA, Clara. The Inter-American court of human rights: theory and practice, present and future. Cambridge: Intersentia, 2015. p. 265-266, 276; PELAYO MÖLLER, Carlos María. El "mínimo vital" como estándar para la justiciabilidad de los derechos económicos, sociales y culturales. Méthodos, v. 3, p. 31 51, 2012. p. 40; SALVIOLI, Fabián. La protección de los derechos económicos, sociales y culturales en el sistema interamericano de derechos humanos. Revista IIDH, v. 39, p. 101-167, 2004. p. 112113, 156; FAÚNDEZ LEDESMA, Héctor. La justiciabilidad de los Derechos Sociales em el Derecho Internacional Contemporâneo. Gaceta Laboral, v. 6, n. 2, p. 163-200, 2000. p. 193.

11 ABRAMOVICH, Víctor; ROSSI, Julieta. La tutela de los derechos económicos, sociales y culturales en el artículo 26 de la Convención Americana sobre Derechos Humanos. Revista Estudios Socio-Juridicos, v. 9, n. esp., p. 34-53, abr. 2007. p. 46. Ainda que formulada com base no direito constitucional brasileiro e sem desconsiderar que a realização de direitos sociais deve considerar certa conjuntura socioeconômica, cabe aqui mencionar a crítica realizada por Sarlet ao que denominou de uma postura ideológica aquela pautada na desqualificação dos direitos sociais como direitos humanos (fundamentais no caso da caso da Constituição brasileira), incluída nessa classificação a criação de barreiras intransponíveis para sua implementação. SARLET, Ingo Wolfgang. A eficácia dos direitos fundamentais: uma teoria geral dos direitos fundamentais na perspectiva constitucional. 13. ed. Porto Alegre: Livraria do Advogado, 2018. p. 364. Sobre a eficácia normativa de normas programáticas, veja-se ainda o entendimento de Grau. GRAU, Eros Roberto. A ordem econômica na Constituição de 1988: interpretação e crítica. 18 ed. São Paulo: Malheiros, 2017. p. 355. E quanto a exigibilidade dos DESC desde uma perspectiva de direito internacional, veja-se entendimento de Abramovich e Courtis. ABRAMOVICH, Víctor; COURTIS, Christian. Hacia la exigibilidad de los derechos económicos, sociales y culturales. Es- 


\subsection{Abordagem desfavorável}

Em uma outra vertente interpretativa das normas que compõem o Sistema Interamericano de Direitos Humanos, muito embora o PSS disponha sobre uma estreita relação entre os DCP e os DESCA, basicamente se entende que o art. 19.6 seria claro ao referir que somente os direitos sindicais constantes no art. 8.a e o direito à educação previsto no art. 13 podem ser judicializados mediante o sistema de petições individuais regulado pela $\mathrm{CADH}$, isto é, somente os direitos consagrados nesses dois artigos gozariam de justiciabilidade direta perante a Corte IDH.

Os argumentos dessa corrente contrária à justiciabilidade direta dos DESCA não exigem muitos detalhes para serem expostos e compreendidos. Basicamente, as linhas de fundamentação que embasam a não justiciabilidade direta dos DESCA partem da ideia de que o art. 26 da CADH não conteria direitos específicos e exigíveis individualmente ${ }^{12}$. Também, argumenta-se que as violações aos DESCA, principalmente aqueles expressamente previstos no PSS que não dissessem respeito aos artigos 8.a e 13 ali previstos não seriam submetidos ao sistema de petições individuais ${ }^{13} \mathrm{e}$, portanto, careceriam de fundamento jurídico para que fossem exigidos diretamente.

Para essa corrente contrária, não haveria como extrair da CADH qualquer possibilidade jurídica para reforçar a justiciabilidade direta dos DESCA, isso porque

tándares internacionales y criterios de aplicación ante los tribunales locales. In: ABRAMOVICH, Víctor; BOVINO, Alberto; COURTIS, Christian. La aplicación de los tratados sobre derechos humanos por los tribunales locales. Buenos Aires: Editores del Puerto, 2004. p. 304.

12 CAVALlARO, James L.; SCHAFFER, Emily J. Less as More: rethinking supranational litigation of economic and social rights in the Americas. Hastings Law Journal, v. 56, p. 217-282, 2004; AVALLARO, James L.; SCHAFFER, Emily J. Less as More: Rethinking Supranational Litigation of Economic and Social Rights in the Americas. Hastings Law Journal, v. 56, p. 217-282, 2004, p. 225; RUIZCHIRIBOGA, Oswaldo R. The American Convention and the Protocol of San Salvador: two intertwined treaties: non-enforceability of economic, social and cultural rights in the inter-american system. Netherlands Quarterly of Human Rights, v. 31, n. 2, p. 159-186, 2013. p. 182.

13 CAVALLARO, James L.; SCHAFFER, Emily J. Less as More: rethinking supranational litigation of economic and social rights in the Americas. Hastings Law Journal, v. 56, p. 217-282, 2004. p. 268269; RUIZ-CHIRIBOGA, Oswaldo R. The American Convention and the Protocol of San Salvador: two intertwined treaties: nonenforceability of economic, social and cultural rights in the interamerican system. Netherlands Quarterly of Human Rights, v. 31, n. 2, p. 159-186, 2013. p. 161, 176. o art. 26, isto é, o único artigo que compõe o Capítulo III da CADH, intitulado "Direitos Econômicos, Sociais e Culturais", não faria menção a qualquer direito de maneira expressa e, como consequência, não haveria exigibilidade individual de direitos possível de ser fundamentada a partir de seu enunciado.

Além disso, para essa abordagem, embora o PSS contivesse um não curto rol contendo previsões sobre os DESCA, a justiciabilidade direta do seu conteúdo seria limitada expressamente por força do art. 19.6, que permitiria a justiciabilidade direta única e exclusivamente dos direitos previstos nos artigos 8.a e 13.

Além dessas duas fundamentações que preenchem um amplo espaço argumentativo da corrente contrária, poderia se aventar uma terceira controvérsia, que trataria sobre os limites da Corte IDH em seus julgamentos de casos contenciosos que tratassem sobre os DESCA à luz do reconhecimento de sua justiciabilidade direta com base no art. 26 da CADH.

Esse entendimento, apesar de que pudesse vir a reconhecer direitos tendo como esteio o art. 26 da CADH, pautaria sua contrariedade com base nos limites do próprio art. 26, que teria estabelecido, apenas, um caminho progressivo de plena efetivação dos DESCA, bem como imposto a observação de eventuais restrições orçamentárias para a efetivação progressiva dos DESCA. Porém, essa não parece ser, por si só, uma limitação à justiciabilidade direta dos DESCA, mas apenas uma questão sobre os limites da Corte IDH na sua atuação jurisdicional sobre os DESCA. Seria muito mais uma questão de aplicação e interpretação dos DESCA em casos concretos do que um argumento contrário à justiciabilidade direta destes direitos.

E, se da corrente argumentativa recém-exposta, a não justiciabilidade direta fosse defendida em razão de uma possível classificação desses direitos como sendo de aplicação progressiva, haveria uma incompreensão a respeito da dogmática dos direitos humanos, pois, mesmo se tratando de um direito de aplicação progressiva, ainda assim não estariam excluídas as possibilidades de sua judicialização. 


\section{Justiciabilidade direta dos DESCA na Corte IDH}

Ainda antes de um novo rumo das decisões proferidas pela Corte IDH a respeito da justiciabilidade dos DESCA — ser tomado, desde há muito já se apontava uma relação intrínseca entre os direitos humanos, ainda que resguardassem, em sua essência, bens jurídicos diversos. Nesse sentido, Cançado Trindade manifestava uma espécie de aceitação virtual universal da tese de uma interrelação e indivisibilidade dos direitos humanos ${ }^{14}$. Apesar desse entendimento prévio que favorecia a exigibilidade dos DESCA, ainda que indireta e reflexamente, na última década, a Corte IDH proferiu uma série de decisões favoráveis à justiciabilidade direta dos DESCA.

Nesse sentido, há uma reconstrução possível de ser realizada com base nos casos que levaram ao entendimento da viabilidade da justiciabilidade direta do art. 26 da CADH. Essa narrativa decorre da interpretação de um longo processo que dependeu de diversas composições da Corte IDH, de certos votos de seus juízes membros sobre variados temas e de diferentes contextos políticos do Sistema Interamericano de Direitos Humanos, o que levou Parra Vera a descrever essa forma de interpretação, metaforicamente, como sendo uma novela em cadeia ${ }^{15}$. Nada obstante, das decisões judiciais da Corte IDH que reforçaram e conformaram a justiciabilidade direta dos DESCA, não é de se ignorar que quatro casos despontam como verdadeiros marcos na trajetória deste entendimento. São eles: Acevedo Buen-

\footnotetext{
14 TRINDADE, Antônio Augusto Cançado. La protección internacional de los derechos, econômicos, sociales y culturales. In: CERDAS CRUZ, Rodolfo; NIETO LOAIZA, Rafael. Estudios básicos de derechos humanos. San José: IIDH, 1994. p. 60.

15 PARRA VERA, Óscar. La justiciabilidad de los derechos económicos, sociales y culturales en el Sistema Interamericano a la luz del artículo 26 de la Convención Americana. El sentido y la promesa del caso Lagos del Campo. In: FERRER MAC-GREGOR, Eduardo; MORALES ANTONIAZZI, Mariela; FLORES PANTOJA, Rogelio. Inclusión, Ius Commune y justiciabilidad de los DESCA en la jurisprudencia interamericana: el caso Lagos del Campo y los nuevos desafios. Querétaro: Instituto de Estudios Constitucionales del Estado de Querétaro, 2018. p. 182. Veja-se, a respeito, a ideia de novela em cadeia (Chain Novel) de Dworkin que inspirou Parra Vera, segundo a qual os juízes são ao mesmo tempo autores e críticos e uma decisão judicial inclui em uma tradição a interpretação de um determinado juiz, ao ponto que os juízes futuros confrontarão uma nova tradição que inclui aquilo que o juiz anterior decidiu, e assim por diante. DWORKIN, Ronald. Law's empire. Cambridge: The Belknap Press of Harvard University Press, 1986. p. 228.
}

día y otros vs Perú (2009), Lagos del Campo vs Perú (2017), Cuscul Pivaraly otros Vs. Guatemala (2018) e Lhaka Honbat vs. Argentina (2020).

É possível pontuar, nos quatro casos destacados e extraídos dos precedentes da Corte IDH, as mudanças ocorridas na trajetória de decisões proferidas por aquele Tribunal. Isso implica uma análise contextual e dos principais pontos decididos em cada um dos casos, estabelecendo-se uma relação direta com o que se pretende demonstrar neste artigo; é dizer, os rumos tomados quanto à exigibilidade direta dos DESCA frente à Corte IDH. Portanto, esta análise com detalhes selecionados dos precedentes, como se poderá facilmente perceber logo adiante, não contém descrições pormenorizadas de cada um dos casos, o que, além de fugir do propósito do estudo realizado, ultrapassaria os limites espaciais deste texto.

O caminho que levou à justiciabilidade direta dos DESCA na Corte IDH pode ser identificado por três etapas: (a) uma primeira etapa corresponderia a uma interpretação da Corte IDH pouco promissora em relação à justiciabilidade direta dos DESCA por não conter efeitos concretos; (b) uma segunda etapa remete ao momento em que a Corte supera e retifica a interpretação anteriormente conferida ao art. 26 da CADH e admite uma diversa linha hermenêutica; (c) por fim, a recente terceira etapa adota um caminho de justiciabilidade direta dos direitos sociais com base em uma interpretação expansiva das possibilidades decorrentes da norma contida no art. 26 da CADH. ${ }^{16}$

Neste estudo, tem-se como proposta realçar a segunda e a terceira etapas pelas quais a Corte passou em seu desenvolvimento jurisprudencial sobre a justiciabilidade direta do art. 26 da CADH, uma vez que a primeira etapa, justamente por adotar uma linha interpretativa diversa, não condiz com o desenvolvimento jurisprudencial posteriormente ocorrido ${ }^{17}$. Mesmo assim, com

\footnotetext{
16 ROSSI, Julieta. Punto de inflexión en la jurisprudencia de la Corte Interamericana de Derechos Humanos sobre DESCA: el camino de la justiciabilidad directa: de "Lagos del Campo" a "Asociación Lhaka Honhat". Pensar en Derecho, Buenos Aires, v. 16, p. 183-235, jul. 2020. p. 192.

17 Para um inventário detalhado sobre as decisões da Corte IDH que culminaram no estágio atual. PARRA VERA, Óscar. La justiciabilidad de los derechos económicos, sociales y culturales en el Sistema Interamericano a la luz del artículo 26 de la Convención Americana. El sentido y la promesa del caso Lagos del Campo. In: FERRER MAC-GREGOR, Eduardo; MORALES ANTONIAZZI, Mariela; FLORES PANTOJA, Rogelio. Inclusión, Ius Commune y justi-
} 
vistas a ilustrar essa linha de entendimento primária, é emblemática a decisão da Corte IDH sobre a interpretação do art. 26 da CADH no caso Cinco Pensionistas vs. Perú ${ }^{18}$.

Em 2003, no mencionado caso Cinco Pensionistas vs. Perú, pela Corte IDH foram analisadas as alegações de que o Estado peruano houvera adotado medidas regressivas com relação ao direito à seguridade social, além de violar o direito à propriedade e à tutela judicial efetiva, por ter o Estado modificado, arbitrariamente, as pensões que seriam pagas às vítimas e não cumprido com os pagamentos ordenados em sentenças judiciais de ações pelas vítimas ajuizadas. Ao abordar uma possível violação ao art. 26, a Corte IDH determinou que o dever de desenvolvimento progressivo e a proibição de regresso somente poderiam ser medidas com relação à totalidade da população e não apenas com base em um grupo de pessoas, então considerado como não representativo da situação geral ${ }^{19}$.

Após essas questões introdutórias ao capítulo, passa-se, nos próximos tópicos, a considerar, separadamente, as decisões então tidas como fundamentais para expor, em uma narrativa sequencial, o caminho interpretativo adotado pela Corte IDH em direção à justiciabilidade direta dos DESCA.

\subsection{Caso Acevedo Buendía y otros vs Perú (2009): afirmação de competência da Corte para se pronunciar sobre o art. 26 da $\mathrm{CADH}$}

O caso Acevedo Buendía y otros (Cesantes y Jubilados de la Contraloría) vs Perí ${ }^{20}$ tratou de uma demanda de 273 pensionistas membros da Asociación de Cesantes y Ju-

ciabilidad de los DESCA en la jurisprudencia interamericana: el caso Lagos del Campo y los nuevos desafios. Querétaro: Instituto de Estudios Constitucionales del Estado de Querétaro, 2018. p. 196 et seq. Sobre o tema, veja-se ainda, cf. PIOVESAN, Flávia; MORALES ANTONIAZZI, Mariela; CUNHA CRUZ, Julia Cortez da. La protección de derechos sociales en la Comisión Interamericana de Derechos Humanos. In: MORALES ANTONIAZZI, Mariela; RONCONI, Liliana; CLÉRICO, Laura. Interamericanización de los DESCA: El caso Cuscul Pivaral de la Corte IDH. Querétaro: Instituto de Estudios Constitucionales del Estado de Querétaro, 2020, p. 190 et seq.

18 CORTE IDH. Caso "Cinco Pensionistas" Vs. Perú. Fondo, Reparaciones y Costas. Sentencia de 28 de febrero de 2003. Serie C No. 98.

19 CORTE IDH. Caso "Cinco Pensionistas" Vs. Perú. Fondo, Reparaciones y Costas. Sentencia de 28 de febrero de 2003. Serie C No. 98, parágrafo 147.

${ }^{20}$ CORTE IDH. Caso Acevedo Buendía y otros ("Cesantes y Jubilados de la Contraloría") Vs. Perú. Excepción Preliminar, Fondo, Reparaciones y Costas. Sentencia de 1 de julio de 2009. Serie C No. 198. bilados de la Contraloría General de la República. Os pensionistas, da membros da Associação, recebiam uma pensão progressivamente nivelada com a remuneração do titular em atividade da que viera a ocupar o mesmo cargo ou função análoga a que os pensionistas desempenhavam ao tempo de sua aposentadoria. Porém, uma nova norma editada em 1992 tolheu esses benefícios, a redução dos valores percebidos foi entendida como inconstitucional pelo Tribunal Constitucional do Peru.

A Corte IDH foi chamada a se manifestar sobre o fato de que, dentre os períodos de abril de 1993 a outubro de 2002, os membros da associação receberam valores não nivelados e, consequentemente, a menor em relação ao que era determinado antes da norma de 1992 que cortou o benefício, uma vez que o Estado do Peru passou a realizar o pagamento das pensões a partir de 2002 sem cumprir com a restituição dos valores não pagos no período antecedente. $\mathrm{Na}$ ocasião, os membros da Associação alegaram violações ao direito à proteção judicial e ao direito de propriedade, previstos nos artigos 25 e 21, respectivamente, da CADH.

Quanto ao art. 25, a Corte IDH entendeu, por unanimidade, que o Estado peruano falhou em assegurar uma aplicação de recursos efetivos ante autoridades competentes que venham a proteger pessoas sob sua jurisdição contra atos que violem seus direitos fundamentais ou que conduzam à determinação de seus direitos e deveres, conforme determinava o art. $25.1 \mathrm{da}$ CADH. Também, consoante a Corte IDH, o Estado peruano não cumpriu com sua função de garantir os mecanismos hábeis a executar as decisões e sentenças definitivas emanadas pelas autoridades competentes com a finalidade de proteger os direitos declarados e reconhecidos, de acordo com o art. 25.2c da CADH. Foi declarada, com isso, a violação do direito à proteção judicial reconhecida nos artigos 25.1 e 25.2c, em relação ao art. 1.1, todos da $\mathrm{CADH}^{21}$.

E, sobre o direito de propriedade, a Corte IDH entendeu que com a redução ilegal dos valores auferidos pelos membros das Associações, houve uma afetação direta em seu patrimônio, de modo que não puderam gozar, integralmente, de seu direito de propriedade sobre os efeitos patrimoniais de sua pensão nivelada.

${ }^{21}$ CORTE IDH. Caso Acevedo Buendía y otros ("Cesantes y Jubilados de la Contraloria") Vs. Perú. Excepción Preliminar, Fondo, Reparaciones y Costas. Sentencia de 1 de julio de 2009. Serie C No. 198, parágrafos 72 e 79 . 
Persistindo uma afetação ao patrimônio das vítimas enquanto o Estado do Peru não restituir os valores retidos entre abril de 1993 a outubro de 2002. Desse modo, a Corte IDH concluiu que a prolongada e injustificada não observância das decisões judiciais internas levou à vulneração do direito de propriedade reconhecido no art. 21 da CADH, precisamente os artigos 21.1 e 21.2, em relação ao art. 1.1, todos da CADH.

E, mesmo entendendo pela ausência de violação ao art. 26 da CADH por compreender terem sido violados, apenas, os direitos protegidos pelos artigos $25 \mathrm{e}$ 21, também da CADH e em razão de não fazer parte da controvérsia se os membros da Associação tinham direito ao nivelamento da pensão ${ }^{22}$, a Corte IDH se manifestou no sentido de que o art. 26 da CADH se conjuga com a primeira parte do referido tratado, sobre os deveres estatais, e está sujeito às obrigações gerais contidas nos artigos 1.1 e 2 do Capítulo I da CADH, de igual forma aos DCP. Com isso, a Corte IDH ressaltou a interdependência entre os DCP e os DESC. Deveriam ser compreendidos integralmente como direitos humanos, sem hierarquia e exigíveis em todos os casos ante as autoridades competentes, sendo até mesmo passíveis de justiciabilidade as regressões causadas aos DESC, ainda que de forma condicionada e passível de serem justificas por questões de peso ${ }^{23}$.

Destaca-se, nessa decisão, ainda, o voto do juiz García Ramírez, a respeito das limitações da Corte IDH em desenvolver e interpretar o art. 26 da $\mathrm{CADH}$, tanto em razão do corpus juris interamericano como devido aos casos que chegaram à Corte. Sobre isso, García Ramírez conclui que a Corte IDH entende ser exigivel a observância do art. 26 da CADH como norma imperiosa,

${ }^{22}$ CORTE IDH. Caso Acevedo Buendía y otros ("Cesantes y Jubilados de la Contraloria") Vs. Perú. Excepción Preliminar, Fondo, Reparaciones y Costas. Sentencia de 1 de julio de 2009. Serie C No. 198, parágrafos 106 e 107.

23 CORTE IDH. Caso Acevedo Buendía y otros ("Cesantes y Jubilados de la Contraloría") Vs. Perú. Excepción Preliminar, Fondo, Reparaciones y Costas. Sentencia de 1 de julio de 2009. Serie C No. 198, parágrafos 100, 101 e 103. Neste ponto, há que se observar a crítica de Catoggio, ao referir que se tratando de uma proibição e retrocesso e sendo discutível apenas como se daria o desenvolvimento progressivo, seria injustificado um condicionamento das obrigações de não regressividade que impõem o cumprimento com os DESC. CATOGGIO, Augusto. El largo y controvertido camino en la protección de los derechos sociales: acerca del caso Acevedo Buendía y otros (cesantes y jubilados de la Contraloría) vs. Perú (2009, Cr.I.D.H.). Revista Relaciones Internacionales, n. 38, 2010. Disponible en: http://sedici.unlp. edu.ar/bitstream/handle/10915/46542/Documento_completo_. pdf? sequence $=1 \&$ isAllowed $=y$. Acceso en: 01 nov. 2020 . não se tratando, apenas, de sugestão política, mediante uma valoração de duas dimensões, uma sobre a progressividade e a outra sobre a proibição de regresso.

No julgamento de 2009, mesmo que a Corte IDH não tenha se manifestado pela ocorrência de uma violação específica ao art. 26 da CADH, deixou o tribunal um inquestionável entendimento sobre a justiciabilidade direta dos direitos interpretados com base no art. 26 da CADH.

Ao comentar a decisão proferida pela Corte IDH, Piovesan destaca ter sido reconhecido pela Corte que os direitos humanos devem ser interpretados sob a perspectiva de sua integralidade e interdependência, conjugando-se os DCP aos DESC sem qualquer hierarquia, de modo a serem todos os direitos exigíveis. Conforme esclareceu Piovesan, a Corte destacou, também, que a aplicação progressiva dos direitos sociais é suscetível de controle e fiscalização pelas instâncias competentes, com realce para o dever dos Estados de não imporem regressos em matéria de direitos sociais ${ }^{24}$.

$\mathrm{Na}$ decisão, a Corte IDH se manifestou, favoravelmente, à justiciabilidade direta do art. 26 da CADH, estabelecendo que a progressividade implica uma direta obrigação dos Estados de não regressão na proteção dos DESC $^{25}$. A ausência de menção a uma violação de um dos DESC baseada, unicamente, no art. 26 da CADH, não retira o fato de ter sido utilizada a ideia de progressividade contida no referido artigo para interpretar possíveis violações a direitos incluídos na CADH. ${ }^{26}$

Conforme Parra Vera, serviu o caso Acevedo Buendía vs. Perú como um primeiro passo para superar dúvidas pretéritas, tendo a Corte IDH se manifestado, positivamente, sobre a possibilidade de que o art. 26 da CADH, ao concretizar direitos econômicos, sociais e culturais fosse exigível, recaindo sobre este rol de direitos obriga-

\footnotetext{
24 PIOVESAN, Flávia. Direitos humanos e diálogo jurisdicional no contexto latino-americano. In: BOGDANDY, Armin von; PIOVESAN, Flávia; ANTONIAZZI, Mariela Morales. Direitos humanos, democracia e integração jurídica: emergência de um novo direito público. Rio de Janeiro, Elsevier, 2013. p. 403.

25 SEATZU, Francesco; TORRES, Amaya Ubeda de. The social charter of the OAS: a step forward in the enforcement of socioeconomic rights in the Americas? Netherlands Quarterly of Human Rights, v. 32, n. 2, p. 130-158, 2014. p. 149.

26 SEATZU, Francesco; TORRES, Amaya Ubeda de. The social charter of the OAS: a step forward in the enforcement of socioeconomic rights in the Americas? Netherlands Quarterly of Human Rights, v. 32, n. 2, p. 130-158, 2014. p. 151.
} 
ções de respeito e garantia, tais como prevenção, proteção e cumprimento ${ }^{27}$.

\subsection{Caso Lagos del Campo vs Perú (2017): primeira declaração de violação de direitos laborais a partir do art. 26 da $\mathrm{CADH}$}

Com a decisão Lagos del Campo us Perü28, a CIDH pela primeira se manifestou por uma condenação com base especificamente no art. 26 da CADH, notadamente com base nos direitos à estabilidade laboral e com fundamento extraído da combinação do art. $26 \mathrm{com}$ os artigos 1.1, 8, 13 e 16 da CADH. Também, declarou a Corte vulnerados os direitos à liberdade de expressão (artigos 8 e 13, combinado com o art. 1.1, da CADH), o direito à liberdade de associação (artigos 16 e 26, combinado com os artigos 1.1, 8 e 13 da CADH) e o direito de acesso à justiça (artigos 8 e 25, também da CADH).

Versava o caso sobre a demissão por justa causa de Alfredo Lagos del Campo, um membro de uma comunidade de industriários do Peru demitido em 1989 por se manifestar, criticamente, à empresa em que trabalhava na época. Após o Poder Judiciário peruano ter negado a reintegração ao emprego e considerado justa a demissão, a representação judicial encaminhada por Alfredo Lagos del Campo à Comissão Interamericana causou o processamento do Estado do Peru junto à Corte IDH.

Extrai-se da decisão proferida pela Corte IDH uma declaração de violações a direitos relativos à matéria laboral, com base no art. 26 da CADH, em duas situações específicas, sendo elas a estabilidade laboral e a liberdade de associação de trabalhadores.

Versando sobre a estabilidade laboral, é referido na decisão um direito próprio da Corte de resolver qualquer controvérsia relativa à sua jurisdição, ocasião em que menciona, expressamente, o precedente do caso Acevedo Buendía y otros vs Perú e exerce uma interpretação

\footnotetext{
${ }^{27}$ PARRA VERA, Óscar. La justiciabilidad de los derechos económicos, sociales y culturales en el Sistema Interamericano a la luz del artículo 26 de la Convención Americana. El sentido y la promesa del caso Lagos del Campo. In: FERRER MAC-GREGOR, Eduardo; MORALES ANTONIAZZI, Mariela; FLORES PANTOJA, Rogelio. Inclusión, Ius Commune y justiciabilidad de los DESCA en la jurisprudencia interamericana: el caso Lagos del Campo y los nuevos desafios. Querétaro: Instituto de Estudios Constitucionales del Estado de Querétaro, 2018. p. 199.

${ }^{28}$ CORTE IDH. Caso Lagos del Campo vs Peru. Excepciones Preliminares, Fondo, Reparaciones y Costas. Sentencia de 31 de agosto de 2017. Serie C No. 340.
}

segundo a qual o art. $26 \mathrm{da} \mathrm{CADH}$, apesar de previsto no Capítulo III sobre os DESC, estaria conjugado com a Parte I da Convenção e, portanto, sujeito às obrigações gerais contidas nos artigos 1.1 e 2, previstos no Capítulo I, assim como estão sujeitos a essas obrigações gerais também os artigos 3 ao 25, pertencentes ao Capítulo II sobre os DCP.

Em vista disso, com base no art. 26 da CADH, a Corte concluiu que a demissão de Alfredo Lagos del Campo acabou privando-o do seu emprego e demais benefícios decorrentes da seguridade social, sem a efetiva tutela do direito à estabilidade laboral por parte do Estado peruano. Com esse entendimento pioneiro da Corte IDH, reconheceu-se, na própria decisão, a concretização de uma específica condenação por violação ao art. 26 da $\mathrm{CADH}^{29}$.

A segunda fundamentação diretamente realizada sobre o art. 26 da CADH tratou da liberdade de associação para fins laborais. Há de se destacar que, conquanto o art. 8.1 a do PSS consagre expressamente o direito de organização e filiação sindical com possibilidade de peticionamento individual, nos termos de seu art. 19.6, a organização a que se encontrava vinculado Alfredo Lagos del Campo possuía natureza distinta dos sindicatos.

A Corte IDH entendeu que o direito à liberdade de associação laboral se estende àquelas organizações que representem os interesses legítimos de trabalhadores, ainda que não sejam classificadas estas organizações como sindicatos. E, conforme a Corte, houve a violação aos artigos 16.1 e 26, em interpretação conjunta com os artigos 1.1, 8 e 13, da CADH. Segundo a fundamentação realizada, as violações ocorreram, em relação ao art. 16, por este prever a liberdade de associação para fins ideológicos, religiosos, políticos, econômicos, trabalhistas, sociais, culturais, desportivos ou de qualquer outra

29 CORTE IDH. Caso Lagos del Campo vs Peru. Excepciones Preliminares, Fondo, Reparaciones y Costas. Sentencia de 31 de agosto de 2017. Serie C No. 340, parágrafo 154. Nos exatos termos da decisão: "Finalmente, cabe señalar que la Corte ha establecido previamente su competencia para conocer y resolver controversias relativas al artículo 26 de la Convención Americana, como parte integrante de los derechos enumerados en la misma, respecto de los cuales el artículo 1.1 confiere obligaciones generales de respeto y garantía a los Estados (supra párr. 142). Asimismo, la Corte ha dispuesto importantes desarrollos jurisprudenciales en la materia, a la luz de diversos artículos convencionales. En atención a estos precedentes, con esta Sentencia se desarrolla y concreta una condena específica por la violación del artículo 26 de la Convención Americana sobre Derechos Humanos, dispuesto en el Capítulo III, titulado Derechos Económicos, Sociales y Culturales de este tratado". 
natureza e, o que importa destacar, em relação ao art. 26, por derivar de normas econômicas, sociais e sobre educação, ciência e cultura, contidas na Carta da OEA, que reconhecem o direito de trabalhadores de associar-se em defesa e promoção de seus interesses.

O marco jurisprudencial decorrente da decisão foi respaldado pelos juízes Caldas e Ferrer Mac-Gregor. Para o primeiro, representou a decisão um grande passo jurisprudencial, tendo sido adotada de modo consciente e maduro. Para o segundo, o caso abriu um rico e novo horizonte para o Sistema Interamericano de Direitos Humanos, tendo ressaltado a sujeição dos Estados ao respeito e garantia aos direitos humanos sem distinção, inclusive aos DESCA.

Dos dois votos dissidentes, provenientes dos juízes Vio Grossi e Sierra Porto, cabe realizar algumas considerações. ${ }^{30}$ Para Vio Grossi, a Corte IDH não poderia conhecer e resolver possível violação ao direito à estabilidade laboral, não sendo um direito reconhecido pela CADH, tampouco passível de amparo pelo sistema de proteção previsto unicamente para os DPC. E, para Sierra Porto, o art. 26 da CADH não conteria um catálogo de direitos, muito pelo contrário, pois apenas prescreveria obrigações da Corte IDH de supervisionar o cumprimento de desenvolvimento progressivo e dever de não retrocesso dos direitos derivados da Carta da OEA. Também, consoante o juiz Sierra Porto, haveria uma vontade expressa dos Estados de não dotar de justiciabilidade os DESCA, salvo as permissões expressamente previstas no art. 19.6 do PSS.

Com a interpretação da Corte IDH sobre o art. 26 da CADH nesse caso, inovou-se em matéria de defesa dos DESCA no Sistema Interamericano de Direitos Humanos. Como referiu Calderón Gamboa, abriu-se uma porta para a justiciabilidade direta desses direitos sempre que o direito em análise cumpra com certos elementos de verificação para sua consolidação como um direito exigível. ${ }^{31}$

\footnotetext{
${ }^{30}$ Ora expostas, as dissidências representam o contraponto realizado pelos juízes na Corte IDH e que mantiveram, com essa base argumentativa, ao longo das decisões posteriores, razão pela qual não voltarão a ser retratados.

31 CALDERÓN GAMBOA, Jorge. La puerta de la justiciabilidad de los derechos económicos, sociales, culturales y ambientales en el Sistema Interamericano: relevancia de la sentencia Lagos del Campo. In: FERRER MAC-GREGOR, Eduardo; MORALES ANTONIAZZI, Mariela; FLORES PANTOJA, Rogelio. Inclusión, Ius Commune y justiciabilidad de los DESCA en la jurisprudencia interamericana: el caso Lagos del Campo y los nuevos desafios. Querétaro: Instituto de
}

Embora, anteriormente ao julgamento, a Corte IDH houvesse se manifestado pela existência dos DESC em outras disposições da CADH, como na ocasião do julgamento do caso Gonalez Lluy Vs. Equador (2015), é certo que, com o julgamento do caso Lagos del Campo vs Perú, foi garantida a justiciabilidade plena desses direitos no Sistema Interamericano por meio único e exclusivo do art. 26 da CADH. ${ }^{32}$

\subsection{Caso Cuscul Pivaral y otros vs. Guatemala (2018): a Corte IDH reconhece uma mudança jurisprudencial}

O caso Cuscul Pivaral y otros vs. Guatemala ${ }^{33}$ tratou da demanda de um grupo de pessoas portadoras do VIH (Vírus da Imunodeficiência Humana) ${ }^{34}$ que padecia de falta de atenção à saúde por parte do Estado ao longo de certo período de tempo, seguido de uma atenção deficiente a partir de determinado momento. Parte das pessoas do grupo faleceu por contraírem a Síndrome da Imunodeficiência Adquirida (SIDA) ${ }^{35}$ e pela consequência de doenças oportunistas, além de que outras permaneceram expostas aos mesmos riscos e passarem por diversas dificuldades.

Ao Corte IDH entendeu pela responsabilidade do Estado da Guatemala em razão da violação do direito à saúde, em conformidade com o art. 26 da CADH em relação ao art. 1.1 e em prejuízo do grupo de pessoas acometidas de VIH. Em conjunto com isso, a Corte

Estudios Constitucionales del Estado de Querétaro, 2018. p. 375. No mesmo sentido. MOSCOSO-BECERRA, Gerson. La justiciabilidad directa de los derechos laborales en la Corte Interamericana de Derechos Humanos. Dikaion, v. 28, n. 2, p. 385-403, 2019. p. 389. 32 MAZZUOLI, Valerio de Oliveria. Curso de direito internacional público. 13 ed. Rio de Janeiro: Forense, 2020. p. 825.

33 CORTE IDH. Caso Cuscul Pivaral y otros Vs. Guatemala. Excepción Preliminar, Fondo, Reparaciones y Costas. Sentencia de 23 de agosto de 2018. Serie C No. 359. É importante observar que meses antes da decisão do caso Cuscul Pivaral y otros vs. Guatemala a Corte IDH, em março de 2018, a Corte IDH proferiu decisão no caso Poblete Vilches y otros vs. Chile em que reconheceu pela primeira vez o direito a saúde de maneira autônoma e exigível com base na $\mathrm{CADH}$, além de fazer referência direta DESCA, isto é, incluindo os direitos ambientais, mediante uma interpretação da Convenção Americana e a incorporação dos DESCA por derivação das normas reconhecidas na Carta da OEA. Nesta decisão, ficou clara a postura da Corte de depreender do artigo 26 duas formas de obrigação, a adoção de medidas gerais progressivas (com concomitante proibição de regresso) e a adoção de medidas de caráter imediato. CORTE IDH. Caso Poblete Vilches y otros V s. Chile. Fondo, Reparaciones y Costas. Sentencia de 8 de marzo de 2018. Serie C No. 349, parágrafos 103, 104 e 105.

34 Human Immunodeficiency Virus (HIV).

35 Acquired Immunodeficiency Syndrome (AIDS). 
IDH entendeu ser responsável o Estado, também, pelas violações à proibição de descriminação, ao Princípio da Progressividade, aos direitos à vida e integridade pessoal, aos direitos de garantias processuais e proteção judicial e à integridade pessoal dos familiares das vítimas.

Ao fundamentar a justiciabilidade do art. $26 \mathrm{da}$ $\mathrm{CADH}$, a Corte IDH utilizou os métodos de interpretação estabelecidos nos artigos 31 e 32 da Convenção de Viena sobre o Direito dos Tratados de 1969, em conjunto com as normas retiradas do art. 29 da CADH, que igualmente tratam de critérios de interpretação. ${ }^{36} \mathrm{E}$, em conclusão, a Corte expressou que, com base em intepretação literal, sistemática e teleológica, o art. 26 da $\mathrm{CADH}$ protege os direitos derivados dos DESC contidos na Carta da OEA. E, como o alcance desses direitos deve ser entendido em relação às demais cláusulas da $\mathrm{CADH}$, eles estão sujeitos às obrigações gerais contidas nos artigos 1.1 e 2, da CADH, e podem ser submetidos à supervisão da Corte, com base nos artigos 62 e 63, igualmente da CADH. Também, a Corte IDH expressou que essa interpretação sobre a justiciabilidade do art. 26 da $\mathrm{CADH}$ se fundamenta conjuntamente com a interpendência e indivisibilidade dos DCP e DESCA, com o objeto e fim da Convenção, que se volta à proteção dos direitos humanos. Com isso, conforme a Corte, tem-se como necessária, em cada caso concreto relacionado à análise dos DESCA, uma análise se da Carta da OEA há uma derivação explícita ou implícita de um direito humano protegido pelo art. $26 \mathrm{da}$ CADH e qual o alcance dessa proteção. ${ }^{37}$

A Corte IDH reiterou que o direito à saúde provém dos DESC contidos na Carta da OEA. O caso Poblete Vilches y otros vs. Chile destacou a natureza e alcance desse direito como contendo tanto aspectos de caráter progressivo, como de exigibilidade imediata ${ }^{38}$.

Ainda, o caso Cuscul Pivaral y otros vs. Guatemala assume um lugar de destaque na jurisprudência interamericana em razão de a Corte IDH ter reconhecido, de modo expresso, claro e, pela primeira vez, a mudança na sua jurisprudência desde o caso Lagos del Campo vs. Perú em relação aos casos anteriormente julgados em que as alegadas violações aos DESCA eram analisadas por co-

\footnotetext{
36 CORTE IDH. Caso Cuscul Pivaraly otros Vs. Guatemala, parágrafo 75.

37 CORTE IDH. Caso Cuscul Pivaraly otros V s. Guatemala, parágrafo 97.

${ }^{38}$ CORTE IDH. Caso Cuscul Pivaral y otros Vs. Guatemala, parágrafo 98.
}

nexidade com algum DCP. A decisão serviu, portanto, para sistematizar e aprofundar, com maior rigor jurídico, os diferentes aspectos desenvolvidos em diversas decisões da Corte IDH sobre o conteúdo, os alcances e a justiciabilidade do art. 26 da $\mathrm{CADH} .{ }^{39}$

O reconhecimento da virada jurisprudencial por parte decisão proferida no caso em análise oportunizou uma ampliação do desenvolvimento argumentativo com a finalidade de concluir, primeiramente, que do art. 26 da CADH se depreendem direitos concretos e, em segundo, que a Corte IDH tem competência para estabelecer violações a esses direitos e fixar reparações. ${ }^{40}$

\subsection{Caso Lhaka Honhat vs. Argentina (2020): o art. 26 da CADH como fundamento para o direito de participar de uma vida cultural, o direito ambiental, o direito à alimentação adequada e o direito à água}

No caso Comunidades Indigenas Miembros de la Asociación Lhaka Honhat (Nuestra Tierra) Vs. Argentina ${ }^{41}$ (doravante abreviado para Lhaka Honhat vs. Argentina) versa-se sobre a reclamação de vários povos indígenas que integram a Lhaka Honhat, uma associação de comunidades indígenas pertencentes aos povos Wichí (Mataco), Iyjwaja (Chorote), Komlek (Toba), Niwackle (Chulupi) y Tapy'y (Tapiete), com a finalidade de que sejam tituladas suas terras de uso tradicional, localizadas no departamento de Rivadavia, na província de Salta da Argentina. Para promover seus interesses, as comunidades indígenas se organizaram criando uma associação, denominada Lhaka Honhat que, no idioma wichí, significa Nossa Terra (Nuestra Tierra). A inércia do Estado em

\footnotetext{
39 IBÁÑEZ RIVAS, Juana Maria. La justiciabilidad directa de los derechos económicos, sociales, culturales y ambientales. Génesis de la innovadora jurisprudencia interamericana. In: MORALES ANTONIAZZI, Mariela; RONCONI, Liliana; CLÉRICO, Laura. Interamericanización de los DESCA: el caso Cuscul Pivaral de la Corte IDH. Querétaro: Instituto de Estudios Constitucionales del Estado de Querétaro, 2020. p. 77.

40 SERRANO GUZMÁN, Silvia. Comentarios sobre el giro jurisprudencial de la Corte Interamericana en materia de justiciabilidad de los derechos económicos, sociales, culturales y ambientales a la luz de seis sentencias emitidas entre 2017 y 2019. In: MORALES ANTONIAZZI, Mariela; RONCONI, Liliana; CLÉRICO, Laura. Interamericanización de los DESCA: El caso Cuscul Pivaral de la Corte IDH. Querétaro: Instituto de Estudios Constitucionales del Estado de Querétaro, 2020, p. 127.

${ }^{41}$ CORTE IDH. Caso Comunidades Indígenas Miembros de la Asociación Lhaka Honbat (Nuestra Tierra) Vs. Argentina. Fondo, Reparaciones y Costas. Sentencia de 6 de febrero de 2020. Serie C No. 400.
} 
titular as terras indígenas foi conjugada ao agravamento da destruição ambiental, como o desmatamento e a destruição dos recursos naturais tais como vegetação e córregos ${ }^{42}$.

A demanda levada à Corte IDH não estava direcionada ao reconhecimento do território como sendo indígena, haja vista que o Estado argentino, de há muito, reconheceu o território ancestral como indígena, identificado pelo governo como sendo aquele localizado nos assim citados Lotes 14 e 55 e que ocupam uma área total de cerca de 643.000 hectares. Procuravam as comunidades indígenas uma determinação em face do Estado, para que este respeitasse e garantisse o direito das comunidades de desfrutar, coletivamente, de suas terras ancestrais.

É relevante notar a proximidade dessa decisão com a Opinião Consultiva OC-23/1743 quanto ao reconhecimento de o direito ao ambiente estar incluído no rol de direitos protegidos pelo art. 26 da $\mathrm{CADH}$, considerando-se a obrigação dos Estados de alcançar um desenvolvimento integral de seus povos mencionada na Carta da OEA, especificamente nos artigos 30, 31, 33 e $34^{44}$.

Além disso, no caso Lhaka Honhat vs. Argentina, a Corte IDH ratificou seu pronunciamento realizado no

\footnotetext{
42 Algumas informações iniciais sobre o caso constam em um relatório produzido pelo Grupo Internacional de Trabajo sobre Asuntos Indígenas (IWGIA) y el Centro de Estudios Legales y Sociales (CELS) anos antes de seu julgamento final pela Corte IDH. CARRASCO, Morita; ZIMMERMAN, Silvina. Argentina: el caso Lhaka Honhat. Buenos Aires: IWGIA, 2006.

${ }^{43}$ CORTE IDH. Medio ambiente y derechos bumanos (obligaciones estatales en relación con el medio ambiente en el marco de la protección y garantía de los derechos a la vida y a la integridad personal - interpretación y alcance de los artículos 4.1 y 5.1, en relación con los artículos 1.1 y 2 de la Convención Americana sobre Derechos Humanos). Opinión Consultiva OC-23/17 de 15 de noviembre de 2017. Serie A No. 23. Para uma análise da competência consultiva da Corte IDH e da solicitação do Estado da Colômbia que deu causa à aludida opinião consultiva, v. GOMES, Eduardo Biacchi; BRANDALISE, Ane Elise. A teoria ambientalista (green theory) e a competência consultiva da Corte Interamericana de Direitos Humanos: o caso da Colômbia. Revista de Direito Internacional, v. 14, n. 3, p. 147159, 2017. p. 153. CORTE IDH. Caso Comunidades Indígenas Miembros de la Asociación Lhaka Honhat (Nuestra Tierra) Vs. Argentina..

${ }^{44}$ CORTE IDH. Fondo, Reparaciones y Costas. Sentencia de 6 de febrero de 2020. Serie C No. 400, parágrafo 202; CORTE IDH. Medio ambiente y derechos humanos (obligaciones estatales en relación con el medio ambiente en el marco de la protección y garantía de los derechos a la vida y a la integridad personal - interpretación y alcance de los artículos 4.1 y 5.1, en relación con los artículos 1.1 y 2 de la Convención Americana sobre Derechos Humanos). Opinión Consultiva OC-23/17 de 15 de noviembre de 2017. Serie A No. 23, parágrafo 57 e nota de rodapé 85 .
}

âmbito da OC-23/17 sobre o conteúdo e alcance do direito ao ambiente, ocasião em que o classificou como um interesse universal e um direito fundamental para a existência da humanidade e que, por ser um direito autônomo, destina-se a proteger os componentes ambientais como interesses jurídicos em si mesmos, mesmo que inexistam evidências sobre riscos a pessoas individuais $^{45}$.

É importante considerar que a Opinião Consultiva, um instrumento de menor grau de confrontação em relação a um caso contencioso e não limitado aos específicos fatos colocados em evidência pela consulta, tem como finalidade contribuir para o desenvolvimento dos direitos humanos internacionais, uma vez que agrega uniformidade e consistência interpretar a Convenção Americana e demais tratados de direitos humanos, além de fornecer expressão judicial aos conceitos de direitos humanos analisados ${ }^{46}$. E a OC-23/17 resultou de uma consulta realizada pelo Estado da Colômbia sobre as obrigações estatais em relação ao ambiente levando em consideração o marco jurídico da proteção e garantia dos direitos à vida e à integridade pessoal, previstos nos artigos 4 e 5 da CADH, em relação aos artigos 1.1 e 2, também da CADH. Por meio da OC-23/17, a Corte IDH se manifestou, pela primeira vez, sobre uma relação intrínseca e necessária, dotada de interdependência, entre os direitos humanos, o ambiente e o desenvolvimento sustentável. Serviu a OC-23/17, com isso, para

${ }_{45}$ CORTE IDH. Caso Comunidades Indígenas Miembros de la Asociación Lhaka Honhat (Nuestra Tierra) Vs. Argentina. Fondo, Reparaciones y Costas. Sentencia de 6 de febrero de 2020. Serie C No. 400, parágrafo 203; CORTE IDH. Medio ambiente y derechos bumanos (obligaciones estatales en relación con el medio ambiente en el marco de la protección y garantía de los derechos a la vida y a la integridad personal - interpretación y alcance de los artículos 4.1 y 5.1, en relación con los artículos 1.1 y 2 de la Convención Americana sobre Derechos Humanos). Opinión Consultiva OC-23/17 de 15 de noviembre de 2017. Serie A No. 23, parágrafos 59 e 62. Sobre a utilização do termo "direito fundamental" na decisão da Corte, embora tenha sido aqui mencionada tal como constou na decisão, faz-se necessário esclarecer que se entende como mais apropriado o emprego da expressão "direitos humanos" por se tratar de termo usualmente utilizado em declarações e convenções internacionais. PEREZ LUÑO, Antonio Enrique. Derechos bumanos, Estado de Derecho y Constitucion. 5 ed. Madrid: Tecnos, 1995. p. 31. Sobre essa perspectiva, veja-se, também, SARLET, Ingo Wolfgang. A eficácia dos direitos fundamentais: uma teoria geral dos direitos fundamentais na perspectiva constitucional. 13. ed. Porto Alegre: Livraria do Advogado, 2018. p. 29.

46 PASQUALLI, Jo M. The practice and procedure of the Inter-American Court of Human Rights. 2 ed. Cambridge: Cambridge University Press, 2013. p. 80. 
demonstrar a tendência da Corte IDH na matéria referente à justiciabilidade dos DESCA ${ }^{47}$.

Dentre os diversos fundamentos expressados pela Corte IDH no caso Lhaka Honhat vs. Argentina ao decidir sobre os direitos à alimentação, à água e de participação à vida cultural, tanto com base no ordenamento jurídico internacional como a partir do direito doméstico aplicáveis ao caso, destacam-se fundamentos extraídos que diretamente se associam a uma interpretação da Corte em prol da justiciabilidade direta desses direitos. Assim o direito à alimentação adequada foi considerado mediante a disposição do art. 34.j da Carta da OEA e consoante o art. XI da Declaração Americana ${ }^{48}$. Sobre o direito à água, a Corte seguiu o caminho interpretativo em relação ao art. 26 da CADH e a demonstração de derivação desse direito a partir da Carta de $\mathrm{OEA}^{49}$. E a respeito do direito de participação à vida cultural, incluso o direito de identidade cultural, a Corte IDH fundamentou com base na Carta da OEA, inclusive associando-o ao direito à alimentação adequada e ao direito ao ambiente, especificamente mencionando os artigos 30 , 45 f., 47 e 48, a Carta da OEA e conjuntamente com o art. XIII da Declaração Americana ${ }^{50}$.

Em suas conclusões, entendeu a Corte IDH dentre outras declarações de responsabilidade do Estado argentino, pela sua responsabilidade quanto às violações perpetradas contra o direito de participar de uma vida cultural, no que diz respeito à identidade cultural, ao direito ambiental, ao direito à alimentação adequada e ao direito à água, previstos no art. 26 da CADH em relação ao art. 1.1, também da $\mathrm{CADH}^{51}$.

47 CALDERÓN GAMBOA, Jorge. La puerta de la justiciabilidad de los derechos económicos, sociales, culturales y ambientales en el Sistema Interamericano: relevancia de la sentencia Lagos del Campo. In: FERRER MAC-GREGOR, Eduardo; MORALES ANTONIAZZI, Mariela; FLORES PANTOJA, Rogelio. Inclusión, Ius Commune y justiciabilidad de los DESCA en la jurisprudencia interamericana: el caso Lagos del Campo y los nuevos desafios. Querétaro: Instituto de Estudios Constitucionales del Estado de Querétaro, 2018. p. 375

${ }^{48}$ CORTE IDH. Caso Comunidades Indígenas Miembros de la Asociación Lhaka Honhat (Nuestra Tierra) Vs. Argentina. Fondo, Reparaciones y Costas. Sentencia de 6 de febrero de 2020. Serie C No. 400, parágrafos 210 e 211.

49 CORTE IDH. Caso Comunidades Indigenas Miembros de la Asociación Lhaka Honhat (Nuestra Tierra) Vs. Argentina. Fondo, Reparaciones y Costas. Sentencia de 6 de febrero de 2020. Serie C No. 400, parágrafo 222 .

50 CORTE IDH. Caso Comunidades Indigenas Miembros de la Asociación Lhaka Honhat (Nuestra Tierra) Vs. Argentina. Fondo, Reparaciones y Costas. Sentencia de 6 de febrero de 2020. Serie C No. 400, parágrafo 231 e 232

51 A votação, de três votos contra três, foi desempatada em prol
No julgamento do caso Lhaka Honhat vs. Argentina, pela primeira vez, a Corte IDH se pronunciou em um caso contencioso sobre os direitos relativos ao ambiente, à alimentação adequada, à água e à participação da vida cultura, tendo como eixo normativo o art. 26 da CADH. Nesse caso, vinculando esses direitos aos povos indígenas. Tais direitos foram assegurados no mencionado caso em relação ao direito das comunidades indígenas reclamantes à propriedade ancestral e a um título único sobre a terra que habitam, em função do art. 21 da $\mathrm{CADH}^{52}$

\section{Suporte normativo}

A justiciabilidade direta admitida pela Corte IDH do art. 26 da CADH apresenta-se como a interpretação mais adequada em termos jurídicos. Independentemente das implicações políticas, ao observar de forma sistemática as normas de direito internacional que estão direta ou indiretamente interligadas com o sentido do referido artigo, percebe-se que a postura interpretativa da Corte IDH é sistematicamente mais adequada em relação a qualquer outra possível interpretação. Conforme exposto, o art. 26 da CADH estabelece o compromisso (normativo) da adoção de providências interna e internacionalmente (cooperativamente) de forma progressiva a efetivar os direitos elencados no próprio artigo citado e na Carta da OEA. O fato jurídico sindicável é a violação do desenvolvimento progressivo ${ }^{53}$, ou seja, a regressividade e não efetivação dos direitos referido no art. 26 da CADH.

Sendo fato jurídico que esteja sob a jurisdição da Corte IDH, cabe a esta analisar e julgar. Embora seja lógico esse argumento, a justiciabilidade direta assenta-se, ainda, no PSS que encontra, em seu preâmbulo, a reafirmação dos Estados partes no sentido de "consolidar neste Continente, dentro do quadro das instituições

do reconhecimento da violação em razão do voto de qualidade do Presidente da Corte IDH ser favorável a esse entendimento, observado o artigo 23.3 do Estatuto da Corte.

52 ROSSI, Julieta. Punto de inflexión en la jurisprudencia de la Corte Interamericana de Derechos Humanos sobre DESCA: el camino de la justiciabilidad directa: de "Lagos del Campo" a "Asociación Lhaka Honhat". Pensar en Derecho, Buenos Aires, v. 16, p. 183-235, jul. 2020. p. 211

53 Os exemplos de como a Corte IDH efetuou a análise da violação do artigo 26 da CADH são, e.g., justamente, os casos citados no texto. 
democráticas, um regime de liberdade pessoal e de justiça social, fundado no respeito dos direitos essenciais do homem". Também, destaca-se o art. 4 do PSS que estabelece vedações a restrições e limitações aos direitos reconhecidos ou vigentes pelo e no PSS, mesmo que por legislação interna ou convenções internacionais. Logo, se deseja reafirmar o que foi convencionado, não se pode negar justiciabilidade direta ao art. 26 da CADH, caso contrário retirar-se-iam os efeitos jurídicos do próprio artigo, condicionando-o à necessidade de violação de outros dispositivos e direitos.

Soma-se a isso o art. 1 do PSS, que reforça o art. 26 do $\mathrm{CADH}$, pois estabelece o compromisso dos Estados em adotar as medidas necessárias, especificamente técnica e econômica, interna e internacionalmente, com o objetivo de progressivamente e conforme a legislação interna de cada Estado efetivar os direitos reconhecidos no protocolo. Ainda, caso os Estados não tenham garantido os direitos previstos no PSS, se comprometem adotar as medidas legislativas a fim de torná-las efetivas (art. 2), ou seja, os Estados assumem o compromisso de adotar medidas que se enquadram na ideia do espectro do significado da expressão "desenvolvimento progressivo". O art. 5 especifica o alcance das restrições e limitações ao exercício dos direitos previstos no PSS, que só podem ser limitados ou restritos por leis cujo objetivo é preservar o bem estar geral sem violar o sentido de uma sociedade democrática, sem contrariarem seu propósito e sua razão. Em nenhum desses parâmetros restritivos há a indicação de retrocessividade ao desenvolvimento da efetivação dos direitos previstos no CADH e no PSS.

Se fosse o caso de estabelecer limitações e retirar força normativa do art. 26 da $\mathrm{CADH}$, encontraria resistência no disposto no art. 2, 1, do Estatuto da Corte IDH em relação à sua função jurisdicional em face dos artigos 61, 62 e 63 da CADH. No art. 61, 2, primeira parte, da CADH estabelece-se que a Corte IDH pode conhecer qualquer caso, assim como, no art. 62, 3, primeira parte, também reafirma-se a competência interpretativa e de aplicação da Corte IDH das disposições da CADH, tal como é o caso do artigo 26 da CADH.

\section{Possíveis efeitos e consequências do reconhecimento da justiciabilidade direta dos DESCA}

Após as decisões havidas na Corte IDH, é possível dizer que o tribunal resolveu o debate sobre a justiciabilidade do artigo 26 da $\mathrm{CADH}$, retirando qualquer dúvida de que tanto a Corte como a Comissão IDH analisam as possíveis violações de obrigações relacionadas aos DESCA ${ }^{54}$.

Além disso, podem ser enumerados, brevemente, alguns efeitos que possíveis como decorrentes desse novo entendimento da Corte IDH e que dependerão de análises mais aprofundadas. Uma primeira questão trata do reforço dos DESCA nos países membros pelo desenvolvimento a partir das decisões da Corte IDH, o que pode ser acompanhado de um reconhecimento de igual força normativa e proteção entre as categorias de direitos humanos e uma maior proteção à progressiva efetivação dos DESCA. ${ }^{55}$ Ainda, especificamente no caso do Estado brasileiro, é possível concluir que a atual interpretação Corte IDH está de acordo com o princípio contido no art. $4^{\circ}$, II, da Constituição da República Federativa do Brasi ${ }^{56}$.

No plano do Sistema Interamericano de Direitos Humanos, surge uma possível maior participação da jurisdição internacional em relação a demandas referentes a violações de Direitos Humanos e um maior protagonismo da Corte IDH referente à jurisdição internacional e proteção à manutenção dos DESCA. Isso pode culminar, por consequência direta, em uma ampliação

54 PIOVESAN, Flávia; MORALES ANTONIAZZI, Mariela; CUNHA CRUZ, Julia Cortez da. La protección de derechos sociales en la Comisión Interamericana de Derechos Humanos. In: MORALES ANTONIAZZI, Mariela; RONCONI, Liliana; CLÉRICO, Laura. Interamericanización de los DESCA: El caso Cuscul Pivaral de la Corte IDH. Querétaro: Instituto de Estudios Constitucionales del Estado de Querétaro, 2020. p. 210.

55 Conforme Resende, no caso do Brasil, por exemplo, haveria o dever internacional de cumprir espontânea, imediata e integralmente as decisões da Corte IDH, por força do art. 68 da CADH, inclusive assegurando as implementações das decisões proferidas no âmbito doméstico, considerando que as obrigações convencionais vinculam agentes, órgãos e entidades de Estado. Também, seria possível o ajuizamento de ação judicial executiva com vistas a garantir o cumprimento integral das decisões da Corte IDH. RESENDE, Augusto César Leite de. A executividade das sentenças da corte interamericana de direitos humanos no Brasil. Revista de Direito Internacional, v. 10, n. 2, p. 225-236, 2013. p. 235-236.

56 MASSAÚ, Guilherme. Princípios constitucionais e relacooes internacionais. Porto Alegre: Livraria do Advogado, 2018. 
do aspecto regionalista em face do particularismo, embora o art. $26 \mathrm{da} \mathrm{CADH}$ não ignore as particularidades cultural, social e econômica de cada Estado ${ }^{57}$.

Por fim, nada obsta que desse entendimento da Corte IDH sobre a justiciabilidade direta do art. 26 da CADH advenha uma maior resistência dos Estados partes em reconhecer e respeitar as decisões da Corte, causando desgastes ao órgão e à jurisdição internacional.

\section{Considerações finais}

Neste estudo foram analisados quatro casos julgados pela Corte IDH, selecionados em razão de sua posição emblemática para demonstrar uma nova trajetória interpretativa da Corte IDH, ora favorável à justiciabilidade dos DESCA, sendo os casos, na respectiva ordem: Acevedo Buendía y otros vs Perú (2009), Lagos del Campo vs Perú (2017), Cuscul Pivaral y otros Vs. Guatemala (2018) e Lhaka Honhat vs. Argentina (2020).

Essa guinada favorável à justiciabilidade direta dos DESCA pela Corte IDH reconheceu um entendimento acadêmico que já era esgrimido. Há, com isso, uma condução rumo à consolidação do entendimento favorável à justiciabilidade direta dos DESCA, como explicitam os casos analisados, implicando efeitos não somente no âmbito da Corte IDH, mas que irradiam para todos os Estados membros e submetidos à sua jurisdição, seja pelo fato dos entendimentos da Corte passarem a integrar um catálogo de precedentes passíveis de serem alegados no julgamento por tribunais domésticos, seja por representarem o atual entendimento aplicável no Sistema Internacional de Direitos Humanos sobre os DESCA.

Consequentemente, além de implicar mudanças específicas tendentes a consolidar os DESCA mediante futuras decisões de casos que chegarão à Corte IDH, es-

\footnotetext{
57 PISANÒ, Attilio. I diritti umani come fenômeno cosmopolita: internazionalizzazione, regionalizzazione, specificazione. Milano: Giuffrè, 2011. p. 42. Sobre a margem discricionária dos Estados que existiria com base em questões locais, vale a leitura de estudo sobre a assim denominada teoria da margem nacional de apreciação, realizado por Schäfer, Previdelli e Gomes, inclusive com objetivo de analisar sua aplicação no âmbito do sistema americano, SCHÄFER, Gilberto; PREVIDELLI, José Eduardo Aidikaitis; GOMES, Jesus Tupã Silveira. A margem nacional de apreciação na Corte Interamericana de Direitos Humanos. Revista de Direito Internacional, v. 15, n. 2, p. 324-337, 2018. p. 331.
}

sas decisões, também, refletirão a condução da efetivação desses direitos em nível nacional. Significa dizer que o novel entendimento da Corte IDH possui efeitos que ultrapassam a própria relação entre Estado e ofendido das decisões proferidas, porque reforça o entendimento por meio dos precedentes da Corte, gerando fundamentação jurídica para novos casos a serem decididos. Também, a interpretação da Corte favorável à justiciabilidade direta dos DESCA amplia o que se poderia chamar de cultura jurídica em prol desses direitos, bem como respalda sua necessária observação por todos os Estados que aderiram à $\mathrm{CADH}$ e se submeteram à jurídica da Corte IDH.

Como resultado, tem-se a possibilidade de que a jurisdição internacional da Corte IDH passe a gozar de uma atuação hipertrofiada em casos referentes a violações de direitos humanos, vindo a decidir até mesmo sobre casos que tratam da justiciabilidade direta dos DESCA que anteriormente não teriam chegado à sua jurisdição. Mesmo considerando-se as particilaridades de cada um dos Estados que estivem sob julgamento, haveria um sobrepeso do seu caráter universalista.

Apesar disso, não se pode desconsiderar que, ao reconhecer a justiciabilidade direta dos DESCA, a Corte IDH, inevitavelmente, atrai descontentamento por parte de diversos Estados que não entendem pela justiciabilidade direta dos DESCA com base no art. 26 da CADH. Em casos extremos, esse descontentamento poderia, inevitavelmente, levar a uma resistência desses Estados em dar cumprimento às decisões da Corte, o que criaria desgastes à sua atuação e poderia deslegitimar como órgão jurisdicional internacional.

Entende-se, porém, que essas questões não podem ser respondidas sem uma análise posterior, ao longo do tempo e conforme essas decisões forem ganhando número no rol de precedentes da Corte IDH. Contudo, são conjecturas que servem à finalidade de prevenir possíveis problemas e a conclamar ao aprofundamento de estudos doutrinários sobre essa consolidação jurisprudencial da Corte. 


\section{Referências}

ABRAMOVICH, Víctor; ROSSI, Julieta. La tutela de los derechos económicos, sociales y culturales en el artículo 26 de la Convención Americana sobre Derechos Humanos. Revista Estudios Socio-Jurídicos, v. 9, n. esp., p. 34-53, abr. 2007.

ANTKOWIAK, Thomas. Social, economic, and cultural rights: the Inter-American Court at a Crossroads. In: HAECK, Yves; RUIZ-CHIRIBOGA, Oswaldo; BURBANO-HERRERA, Clara. The Inter-American court of human rights: theory and practice, present and future. Cambridge: Intersentia, 2015.

CALDERÓN GAMBOA, Jorge. La puerta de la justiciabilidad de los derechos económicos, sociales, culturales y ambientales en el Sistema Interamericano: relevancia de la sentencia Lagos del Campo. In: FERRER MAC-GREGOR, Eduardo; MORALES ANTONIAZZI, Mariela; FLORES PANTOJA, Rogelio. Inclusión, Ius Commune y justiciabilidad de los DESCA en la jurisprudencia interamericana: el caso Lagos del Campo y los nuevos desafios. Querétaro: Instituto de Estudios Constitucionales del Estado de Querétaro, 2018.

CARRASCO, Morita; ZIMMERMAN, Silvina. Argentina: el caso Lhaka Honhat. Buenos Aires: IWGIA, 2006.

CATOGGIO, Augusto. El largo y controvertido camino en la protección de los derechos sociales: acerca del caso Acevedo Buendía y otros (cesantes y jubilados de la Contraloría) vs. Perú (2009, Cr.I.D.H.). Revista Relaciones Internacionales, n. 38, 2010. Disponible en: http://sedici.unlp.edu.ar/bitstream/handle/10915/46542/Documento_completo__.pdf? sequence $=1 \&$ is Allowed $=\mathrm{y}$. Acceso en: 01 nov. 2020.

CAVALLARO, James L.; SCHAFFER, Emily J. Less as More: rethinking supranational litigation of economic and social rights in the Americas. Hastings Law Journal, v. 56, p. 217-282, 2004.

CORTE IDH. Caso "Cinco Pensionistas" Vs. Perú. Fondo, Reparaciones y Costas. Sentencia de 28 de febrero de 2003. Serie C No. 98.

CORTE IDH. Caso Acevedo Buendía y otros ("Cesantes y Jubilados de la Contraloría”) Vs. Perú. Excepción Preliminar, Fondo, Reparaciones y Costas. Sentencia de 1 de julio de 2009. Serie C No. 198.
CORTE IDH. Caso Comunidades Indígenas Miembros de la Asociación Lhaka Honhat (Nuestra Tierra) Vs. Argentina. Fondo, Reparaciones y Costas. Sentencia de 6 de febrero de 2020. Serie C No. 400.

CORTE IDH. Caso Cuscul Pivaral y otros Vs. Guatemala. Excepción Preliminar, Fondo, Reparaciones y Costas. Sentencia de 23 de agosto de 2018. Serie C No. 359.

CORTE IDH. Caso Lagos del Campo vs Peru. Excepciones Preliminares, Fondo, Reparaciones y Costas. Sentencia de 31 de agosto de 2017. Serie C No. 340.

CORTE IDH. Caso Poblete Vilches y otros Vs. Chile. Fondo, Reparaciones y Costas. Sentencia de 8 de marzo de 2018. Serie C No. 349.

DWORKIN, Ronald. Law's empire. Cambridge: The Belknap Press of Harvard University Press, 1986.

ESTAPÀ, Jaume Saura. La exigibilidade jurídica de los derechos humanos: especial eferencia a los derechos econômicos, sociales y culturales (DESC). Papeles el Tempo de los Derechos, n. 2, p. 1-14, 2011.

FAÚNDEZ LEDESMA, Héctor. La justiciabilidad de los Derechos Sociales em el Derecho Internacional Contemporâneo. Gaceta Laboral, v. 6, n. 2, p. 163-200, 2000.

GOMES, Eduardo Biacchi; BRANDALISE, Ane Elise. A teoria ambientalista (green theory) e a competência consultiva da Corte Interamericana de Direitos Humanos: o caso da Colômbia. Revista de Direito Internacional, v. 14, n. 3, p. 147-159, 2017.

GRAU, Eros Roberto. A ordem econômica na Constituição de 1988: interpretação e crítica. 18 ed. São Paulo: Malheiros, 2017.

IBÁÑEZ RIVAS, Juana Maria. La justiciabilidad directa de los derechos económicos, sociales, culturales y ambientales. Génesis de la innovadora jurisprudencia interamericana. In: MORALES ANTONIAZZI, Mariela; RONCONI, Liliana; CLÉRICO, Laura. Interamericanización de los DESCA: el caso Cuscul Pivaral de la Corte IDH. Querétaro: Instituto de Estudios Constitucionales del Estado de Querétaro, 2020.

MASSAÚ, Guilherme. Principios constitucionais e relaçoes internacionais. Porto Alegre: Livraria do Advogado, 2018.

MAZZUOLI, Valério de Oliveira; TEIXEIRA, Gustavo de Faria Moreira. O direito internacional do meio ambiente e o greening da Convenção Americana sobre 
Direitos Humanos. Revista Direito GV, São Paulo, v. 9, n. 1, p. 199-242, jan./jun. 2013.

MAZZUOLI, Valerio de Oliveria. Curso de direito internacional público. 13 ed. Rio de Janeiro: Forense, 2020.

MELISH, Tara J. Rethinking the "Less as More" thesis: supranational litigation of economic, social and cultural rights in the Americas. International Law and Politics, v. 39, p. 171-343, 2006.

MOSCOSO-BECERRA, Gerson. La justiciabilidad directa de los derechos laborales en la Corte Interamericana de Derechos Humanos. Díkaion, v. 28, n. 2, p. 385-403, 2019.

PARRA VERA, Óscar. La justiciabilidad de los derechos económicos, sociales y culturales en el Sistema Interamericano a la luz del artículo 26 de la Convención Americana. El sentido y la promesa del caso Lagos del Campo. In: FERRER MAC-GREGOR, Eduardo; MORALES ANTONIAZZI, Mariela; FLORES PANTOJA, Rogelio. Inclusión, Ius Commune y justiciabilidad de los DESCA en la jurisprudencia interamericana: el caso Lagos del Campo y los nuevos desafios. Querétaro: Instituto de Estudios Constitucionales del Estado de Querétaro, 2018.

PASQUALLI, Jo M. The practice and procedure of the InterAmerican Court of Human Rights. 2 ed. Cambridge: Cambridge University Press, 2013.

PELAYO MÖLLER, Carlos María. El "mínimo vital" como estándar para la justiciabilidad de los derechos económicos, sociales y culturales. Méthodos, v. 3, p. 3151, 2012.

PEREZ LUÑO, Antonio Enrique. Derechos humanos, Estado de Derecho y Constitucion. 5 ed. Madrid: Tecnos, 1995.

PIOVESAN, Flávia. Direitos humanos e diálogo jurisdicional no contexto latino-americano. In: BOGDANDY, Armin von; PIOVESAN, Flávia; ANTONIAZZI, Mariela Morales. Direitos humanos, democracia e integração jurídica: emergência de um novo direito público. Rio de Janeiro, Elsevier, 2013.

PIOVESAN, Flávia. Direitos humanos e o direito constitucional internacional. 18 ed. São Paulo: Saraiva Educação, 2018.

PISANÒ, Attilio. I diritti umani come fenômeno cosmopolita: internazionalizzazione, regionalizzazione, specificazione. Milano: Giuffrè, 2011.
RESENDE, Augusto César Leite de. A executividade das sentenças da corte interamericana de direitos humanos no Brasil. Revista de Direito Internacional, v. 10, n. 2, p. 225-236, 2013.

RESENDE, Augusto César Leite de. A tutela jurisdicional do direito humano ao meio ambiente sadio perante a corte interamericana de direitos humanos. Belo Horizonte: Fórum, 2015.

ROSSI, Julieta. Punto de inflexión en la jurisprudencia de la Corte Interamericana de Derechos Humanos sobre DESCA: el camino de la justiciabilidad directa: de "Lagos del Campo" a "Asociación Lhaka Honhat". Pensar en Derecho, Buenos Aires, v. 16, p. 183-235, jul. 2020.

RUIZ-CHIRIBOGA, Oswaldo R. The American Convention and the Protocol of San Salvador: two intertwined treaties: non-enforceability of economic, social and cultural rights in the inter-american system. Netherlands Quarterly of Human Rights, v. 31, n. 2, p. 159-186, 2013.

SALVIOLI, Fabián. La protección de los derechos económicos, sociales y culturales en el sistema interamericano de derechos humanos. Revista IIDH, v. 39, p. 101-167, 2004.

SARLET, Ingo Wolfgang. A eficácia dos direitos fundamentais: uma teoria geral dos direitos fundamentais na perspectiva constitucional. 13. ed. Porto Alegre: Livraria do Advogado, 2018.

SCHÄFER, Gilberto; PREVIDELLI, José Eduardo Aidikaitis; GOMES, Jesus Tupã Silveira. A margem nacional de apreciação na Corte Interamericana de Direitos Humanos. Revista de Direito Internacional, v. 15, n. 2, p. 324-337, 2018.

SEATZU, Francesco; TORRES, Amaya Ubeda de. The social charter of the OAS: a step forward in the enforcement of socioeconomic rights in the Americas? Netherlands Quarterly of Human Rights, v. 32, n. 2, p. 130-158, 2014.

TRINDADE, Antônio Augusto Cançado. La protección internacional de los derechos, econômicos, sociales y culturales. In: CERDAS CRUZ, Rodolfo; NIETO LOAIZA, Rafael. Estudios básicos de derechos humanos. San José: IIDH, 1994. 
Para publicar na Revista de Direito Internacional, acesse o endereço eletrônico www.rdi.uniceub.br ou www.brazilianjournal.org.

Observe as normas de publicação, para facilitar e agilizar o trabalho de edição. 